\title{
Will a perfect model agree with perfect observations? The impact of spatial sampling
}

\author{
Nick A. J. Schutgens ${ }^{1}$, Edward Gryspeerdt ${ }^{2}$, Natalie Weigum ${ }^{1}$, Svetlana Tsyro ${ }^{3}$, Daisuke Goto ${ }^{4}$, Michael Schulz ${ }^{3}$, and \\ Philip Stier ${ }^{1}$ \\ ${ }^{1}$ Department of Physics, University of Oxford, Parks Road, Oxford, OX1 3PU, UK \\ ${ }^{2}$ Institute for Meteorology, University of Leipzig, Stephanstr. 3, 04103 Leipzig, Germany \\ ${ }^{3}$ Norwegian Meteorological Institute, O313 Oslo, Norway \\ ${ }^{4}$ National Institute for Environmental Studies, 16-2 Onogawa, Tsukuba, 305-8568, Japan \\ Correspondence to: Nick A. J. Schutgens (schutgens@ physics.ox.ac.uk)
}

Received: 30 November 2015 - Published in Atmos. Chem. Phys. Discuss.: 19 January 2016

Revised: 25 April 2016 - Accepted: 9 May 2016 - Published: 24 May 2016

\begin{abstract}
The spatial resolution of global climate models with interactive aerosol and the observations used to evaluate them is very different. Current models use grid spacings of $\sim 200 \mathrm{~km}$, while satellite observations of aerosol use so-called pixels of $\sim 10 \mathrm{~km}$. Ground site or airborne observations relate to even smaller spatial scales. We study the errors incurred due to different resolutions by aggregating high-resolution simulations ( $10 \mathrm{~km}$ grid spacing) over either the large areas of global model grid boxes ("perfect" model data) or small areas corresponding to the pixels of satellite measurements or the field of view of ground sites ("perfect" observations). Our analysis suggests that instantaneous rootmean-square (RMS) differences of perfect observations from perfect global models can easily amount to $30-160 \%$, for a range of observables like AOT (aerosol optical thickness), extinction, black carbon mass concentrations, $\mathrm{PM}_{2.5}$, number densities and CCN (cloud condensation nuclei). These differences, due entirely to different spatial sampling of models and observations, are often larger than measurement errors in real observations. Temporal averaging over a month of data reduces these differences more strongly for some observables (e.g. a threefold reduction for AOT), than for others (e.g. a twofold reduction for surface black carbon concentrations), but significant RMS differences remain (10-75\%). Note that this study ignores the issue of temporal sampling of real observations, which is likely to affect our present monthly error estimates. We examine several other strategies (e.g. spatial aggregation of observations, interpolation of model data) for reducing these differences and show their effectiveness. Fi-
\end{abstract}

nally, we examine consequences for the use of flight campaign data in global model evaluation and show that significant biases may be introduced depending on the flight strategy used.

\section{Introduction}

Airborne aerosols are a fascinating component of the Earth's atmosphere. They come in a bewildering variety of shapes, sizes and compositions. More importantly, they can affect the radiative budget and energy and hydrological balances of the atmosphere (Angstrom, 1962; Twomey, 1974; Albrecht, 1989; Hansen et al., 1997; Lohmann and Feichter, 2005, 1997). Dust aerosols may transport nutrients for the biosphere over long distances (Swap et al., 1992; Vink and Measures, 2001; McTainsh and Strong, 2007; Maher et al., 2010; Lequy et al., 2012) and air pollution aerosol can pose health hazards for humans (Dockery et al., 1993; Brunekreef and Holgate, 2002; Ezzati et al., 2002; Smith et al., 2009; Beelen et al., 2013). Aerosols have also been suggested as disease vectors (Ballester et al., 2013). For a recent review of some of these aspects, see Fuzzi et al. (2015).

Models provide powerful tools to explore the role of aerosols, but require evaluations against observations in order to quantify their skill and detect possible model errors. AEROCOM is an international community of scientists (http://aerocom.met.no) involved in evaluating global aerosol models (Kinne et al., 2006; Schulz et al., 2006; Textor et al., 
2006, 2007; Huneeus et al., 2011; Koch et al., 2009; Quaas et al., 2009; Koffi et al., 2012), but model evaluations are also routinely performed by individual research groups around the world. It is therefore surprising that evaluation strategies themselves have received relatively little scrutiny.

Due to constraints on computational resources, global aerosol-climate models are currently run at spatial resolutions of $\sim 200 \mathrm{~km}$. This of course limits their ability to resolve fine-scale structure (Benkovitz and Schwartz, 1997; Weigum et al., 2012) which will affect the comparison of global model data with observations; models and observations represent averages over different spatial areas. Satellite remote sensing observations are made for nominal pixels of $10 \mathrm{~km}$ as for MODIS (MODerate resolution Imaging Spectroradiometer) or $17 \mathrm{~km}$ as for MISR (Multi-angle Imaging SpectroRadiometer) or $3 \mathrm{~km}$ as for SEVIRI (Spinning Enhanced Visible and InfraRed Imager). Ground stations from AErosol RObotic NETwork (AERONET) can be estimated to sample no more than $5 \mathrm{~km}$ horizontally away from the site. In situ measurements cover even less of the atmosphere surrounding them; yet, observed aerosol fields are known to exhibit variations over relatively short distances of 10 to $100 \mathrm{~km}$ (Anderson et al., 2003; Kovacs, 2006; Santese et al., 2007; Shinozuka and Redemann, 2011; Schutgens et al., 2013). Note that the spatial resolution of global models also impacts global model data due to the non-linear nature of many physical and chemical processes (Qian et al., 2010; Gustafson et al., 2011; Stroud et al., 2011; Weigum et al., 2016); but that is not the topic of this paper.

Recently, the disparity of spatial scales between global models and observations has attracted some attention. Using satellite-retrieved solar surface radiation estimates to assess spatial representativeness, Hakuba et al. (2014a, b) estimated differences of $1-2 \%$ and $2-3 \%$, respectively, in 5year seasonal means between either $1^{\circ} \times 1^{\circ}$ or $3^{\circ} \times 3^{\circ}$ areas and point measurements. Cavanaugh and Shen (2015) and Director and Bornn (2015) showed that the standard deviation, skewness and kurtosis of climate data (e.g. temperature) can be significantly different between point values and gridded values (in their analysis means were identical by construction).

We use high-resolution model simulations (with a $10 \mathrm{~km}$ grid spacing) to simulate both perfect global model data and perfect observations. These data are considered perfect in the sense that they are both derived from the same highresolution simulation that we treat as the truth. In fact, the only difference between the global model data and observations is the area over which the high-resolution simulation is averaged (see Sect. 3). No measurement errors are added to the observations. The high-resolution simulations allow us to build up statistics of the difference between observations and model data, under a large variety of scenarios. In particular, we consider different observables like AOT (aerosol optical thickness), $\mathrm{PM}_{2.5}$, number densities and $\mathrm{CCN}$ (cloud condensation nuclei) for different regions on the globe. We also evaluate a variety of averaging and interpolation strategies designed to bring model data and observations closer together. These high-resolution model simulations provide us with a toy model of what happens when global model data are evaluated with observations, ignoring both model and observation errors.

Since we simulate global model data as an average over the high-resolution data, a very relevant question is the following: what average is appropriate? This question is closely tied to the question of what the grid-point value of a global model represents and will be addressed later.

Section 2 introduces the three different models and six different regions for which we have high-resolution simulations. We also explain how the simulated fields were turned into observables. Section 3 describes in more detail how both global model data and observations are generated from the high-resolution simulations. In particular, Sect. 3.1 discusses various interpretations that may be given to a global model's grid-point value. Section 4 then introduces the concept of spatial sampling as a source of error through some examples. More substantive statistics can be found in Sects. 5, 6, 7,8 and 9. An evaluation of several strategies to reduce spatial sampling differences is given in Sect. 10. A preliminary analysis of the consequences of spatial sampling for the use of flight campaign data can be found in Sect. 11. The paper concludes with a summary (Sect. 12).

Note that Sect. 3.2 contains some general guidelines to interpreting many of the figures and statistics that appear in this paper.

\section{The regional models}

Three different regional models were used to create highresolution simulated fields $(10 \mathrm{~km}, 1 \mathrm{~h})$ of common observables: AOT, extinction, $\mathrm{PM}_{2.5}$, black carbon mass concentration, number densities and CCN. Figure 1 shows the simulation regions, and Table 1 summarises the most important information on these simulations.

WRF-Chem (Weather Research and Forecasting model coupled with Chemistry) (Grell et al., 2005; Fast et al., 2006) was run for three regions using the MADE/SORGAM aerosol module (Ackermann et al., 1998; Schell et al., 2001), and one region using the GOCART bulk aerosol scheme. The meteorology was nudged to NCEP-FNL operational analysis data. The western Europe (W. Europe) and Oklahoma runs used emission scenarios (TNO MEGAPOLI-2005 or US National Emissions Inventory NEI-2005) with imposed $24 \mathrm{~h}$ cycles for the anthropogenic emissions. These regions are characterised by fairly localised spatially fixed sources. The Congo experiment used daily biomass burning emissions derived from MODIS fire counts and is characterised by highly localised sources that differ in location from day to day. The MADE/SORGAM module assumes that the aerosol exists in three modes (Aitken, accumulation and coarse) of varying 
Table 1. Simulations analysed in this study.

\begin{tabular}{llllll}
\hline Region & Size $\left(\mathrm{km}^{2}\right)$ & Period & Model & Scheme & Comments \\
\hline W. Europe & $1280 \times 1280$ & May 2008 & WRF-Chem & MADE & two-moment modal \\
Oklahoma & $1190 \times 1190$ & March 2007 & WRF-Chem & MADE & two-moment modal \\
Congo & $2090 \times 2090$ & March 2007 & WRF-Chem & MADE & two-moment modal \\
Ocean & $1270 \times 1270$ & March 2007 & WRF-Chem & GOCART & bulk mass \\
Europe & $4000 \times 3100$ & January-June 2008 & EMEP & & bulk mass \\
Japan & $1500 \times 1250$ & August 2007 & NICAM & \multirow{2}{*}{ SPRINTARS } & bulk mass \\
\hline
\end{tabular}

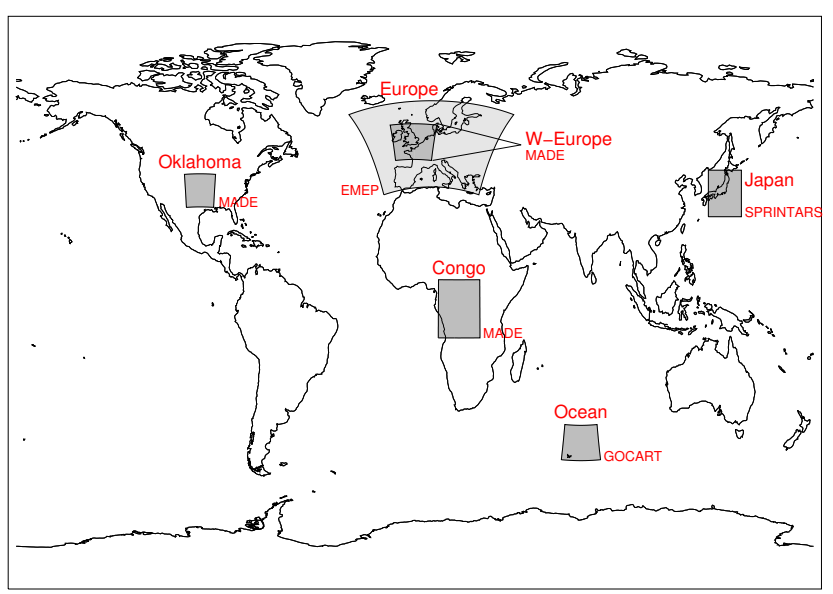

Figure 1. Three models were used in this study to simulate a variety of aerosol fields. The regional names used to identify these simulations are given in large font, while the models are denoted in small font. MADE and GOCART refer to the WRF-Chem version used.

species mixtures (sulfate, nitrate, organic and black carbon, sea salt and dust). MADE/SORGAM explicitly treats nitrates and SOA (secondary organic aerosol).

An expanded version of EMEP/MSC-W (Simpson et al., 2012) that includes calculations of aerosol bulk optical properties (based on work by Hess et al., 1998, and Chin et al., 2002) was run at a $0.1^{\circ} \times 0.1^{\circ}$ grid, using ECMWF-IFS meteorology for 2008 and TNO-INERIS emissions for 2009 for Europe. Emissions of black carbon were derived from the emissions of primary $\mathrm{PM}_{2.5}$, using EMEP standard splitfactors (per country and sector). Monthly, day-of-week and hourly temporal profiles were applied to the annual emissions. The EMEP chemical scheme includes approximately 160 reactions. The aerosols are represented as bulk mass distributed between a fine fraction (including sulfate, nitrate, ammonium, organic and black carbon sea salt and dust) and a coarse fraction (nitrate, sea salt and dust). Ammonium nitrate is calculated with the equilibrium model MARS, and the formation of coarse nitrate from nitric acid depends on the relative humidity. SOA is calculated using the volatility basis set approach. For all details see Simpson et al. (2012) and references therein.
NICAM-SPRINTARS (see Goto et al., 2015, and references therein) was run in global mode with a stretched grid that had a resolution of $11 \mathrm{~km}$ over a part of Honshu (the largest island of Japan). Its meteorology was nudged to NCEP-FNL reanalysis data. SPRINTARS uses a bulk mass scheme with individual modes for sulfate, organic carbon, black carbon and bins for sea salt and dust. Two different organic/black carbon mixtures are also represented by individual modes. Anthropogenic emissions of black carbon and the $\mathrm{SO}_{4}$ precursor gas $\mathrm{SO}_{2}$ had a prescribed diurnal cycle. SOA were treated in the simple manner of scaling aerosol emissions. Nitrate aerosols were ignored in this SPRINTARS simulation.

Both EMEP and SPRINTARS do not calculate number densities as prognostic variables (SPRINTARS can diagnose them from assumed size distributions) and consequently did not provide those fields for our analysis. Both EMEP and SPRINTARS data were regridded from their original model grids to regular grids with $10 \mathrm{~km}$ spacings.

\subsection{Observable parameters}

In this subsection we discuss how well our models are able to simulate aerosol properties (see Table 2) as they would be observed. All of the models provided AOT, extinction and (dry) $\mathrm{PM}_{2.5}$, although WRF-Chem calculates AOT and extinction for $600 \mathrm{~nm}$ and EMEP and NICAM-SPRINTARS for $550 \mathrm{~nm}$

Real black carbon measurements by SP2 (Single Particle Soot Photometer) require a minimum black carbon content per particle. In models with bulk mass schemes, particles either contain only black carbon or none at all. Modal aerosol schemes also cannot properly simulate SP2 measurements, due to the instantaneous redistribution of black carbon mass over many particles of mixed species which leads to very low concentrations per particle (Kipling et al., 2013). We decided to ignore this minimum black carbon content and used the total black carbon concentration as provided by the models.

Real number density measurements dry out the particles before selecting only those above a certain diameter. Hence, N10 and N50 refer to number densities of particles with dry diameters in excess of 10 or $50 \mathrm{~nm}$. WRF-Chem provides only modal number densities at ambient humidities. Based on auxiliary model data, we estimated that "taking out" the 
Table 2. Simulated observables.

\begin{tabular}{lcccccc}
\hline & AOT & Extinction & PM $_{2.5}$ & BC conc. & N10, N50 & CCN \\
\hline WRF-Chem MADE & $\times$ & $\times$ & $\times$ & $\times$ & $\times$ & $\times$ \\
WRF-Chem GOCART & $\times$ & $\times$ & $\times$ & & & \\
EMEP & $\times$ & $\times$ & $\times$ & $\times$ & & \\
NICAM-SPRINTARS & $\times$ & $\times$ & $\times$ & $\times$ & & \\
\hline
\end{tabular}

water has at most a $10 \%$ effect on N10 or N50 values. We also concluded that this may increase the spatial sampling errors we are studying. Furthermore, the model calculates the equilibrium of the ammonia \& nitric acid \& sulfuric acid \& water system (Seinfeld and Pandis, 2006), and "drying out" particles involves much more than simply removing the water (it would lead to a shift in the equilibrium). Currently WRF-Chem provides no mechanism to simulate this aspect of observed number densities, so we decided on a practical approach and use ambient number densities to calculate N10 and N50.

\section{Simulating observational and global model data}

This section briefly describes the main methodology used in this paper. Using the high-resolution simulated fields, we have generated both perfect observations and perfect global model data. The high-resolution field $v$ has a regular rectilinear horizontal grid $(10 \times 10 \mathrm{~km})$, and a regular temporal spacing $(1 \mathrm{~h})$. Only the vertical spacing is non-regular and differs among the models. The field $v$ can be thought of as three- or four-dimensional data cubes $v_{x y t}$ or $v_{x y z t}$ where $x=1 \ldots n_{x}$ and $y=1 \ldots n_{y}$ are indices to the horizontal coordinates, $z=1 \ldots n_{z}$ is an index to the vertical coordinate and $t=1 \ldots n_{t}$ is an index to the time coordinate. In the following, the $z$ coordinate is ignored for brevity's sake. A single perfect observation $O_{x y t}$ at time $t$ and location $x, y$ is simulated by

$O_{x y t}=v_{x y t}$.

A perfect global model grid point's value $M_{x y t}$ can be simulated by averaging $v_{x y t}$ over a global model grid-box area $(2 \Delta x+1) \times(2 \Delta y+1)$ in the high-resolution field:

$M_{x y t}=\sum_{i=-\Delta x}^{\Delta x} \sum_{j=-\Delta y}^{\Delta y} w_{i j} v_{x+i ; y+j ; t}$,

where $\Delta x$ and $\Delta y$ represent the longitudinal and latitudinal half-sizes of a grid box, as measured in the coordinate indices. Here $w$ is a normalised weighting function (to be defined later). Note that perfect model data can only be calculated on an inner domain of the high-resolution region of $1+\Delta x \leq x \leq n_{x}-\Delta x ; 1+\Delta y \leq y \leq n_{y}-\Delta y$.

In the case that the location of the observation and the grid point coincide, an instantaneous spatial sampling error can now be defined as

$\epsilon_{x y t}=O_{x y t}-M_{x y t}$,

where we use the perfect model value as a reference, since it is the model value that we want to evaluate in actual comparisons of observational and model data. It is straightforward to define a relative sampling error for time-averaged data by

$\varepsilon_{x y t}=\left(\sum_{k=t-\Delta t}^{k=t+\Delta t} O_{x y t}-M_{x y t}\right) /\left(\sum_{k=t-\Delta t}^{k=t+\Delta t} M_{x y t}\right)$,

where $2 \Delta t+1$ is an arbitrary averaging interval. Using the global model value (instead of the observation) as reference prevents denominators from becoming zero.

A subset of the data cube of our regional simulations is used to build up error statistics. In addition to the limitation imposed by the Eq. (2) (already discussed), the outer $50 \mathrm{~km}$ of the simulated region was excluded from our analysis to reduce boundary effects. Similarly, the first 2 days of each simulation were used as a spin-up and excluded from analysis. At various points in our analysis, we have studied the sensitivity of our results to these choices but found no significant impact.

\subsection{Interpretation of the grid-point value}

We generate the global model grid-point value $M_{x y t}$ as a weighted average of the high-resolution simulation over a large area; see Eq. (2). The weighting function $w$ represents our interpretation of the global model's grid-point value. The question is as follows: what are realistic $w$ like for actual global models?

A numerical grid with spacing $L$ can represent standing or travelling waves with a wavelength of in theory $2 L$ and in practice $4 L-6 L$. This suggests that the grid-point value of a low-resolution model is at best some average of a highresolution simulation over the grid box $L \times L$. Moreover, at horizontal resolutions of $\sim 200 \mathrm{~km}$, there is no evidence that actual global models have converged numerically (Pope and Stratton, 2002; Roeckner et al., 2006; Williamson, 2008). As the resolution of global models is increased, various aspects of the models are tweaked to obtain best agreement with either observations or reanalysis data sets (see Pope and Stratton for a very clear description). Diffusion is adapted to prevent numerical instabilities and the gravity-wave drag 

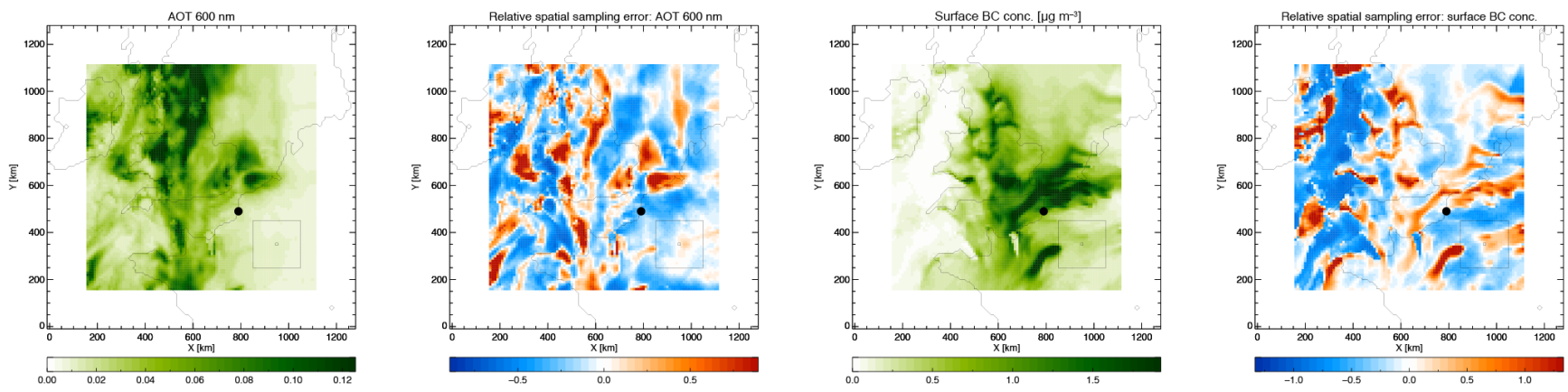

Figure 2. Snapshots of the simulated field and the relative spatial sampling error in the observation of AOT and surface black carbon concentration, over W. Europe exactly 10 days into the simulation by WRF-Chem MADE. Two square boxes $(10 \times 10$ and $210 \times 210 \mathrm{~km})$ and a single location (fat dot), south of Calais, France, are also shown. Note that the high-resolution simulations encompass the whole region shown, while our analysis is only made for the coloured domain.

coefficients are modified according to the resolution of the orography. Best known, various parameters related to subgrid cloud processes are tuned to obtain radiative balance at the top of the atmosphere. Our point here is that the strategy for tweaking the global model to best reflect an observational or reanalysis data set effectively determines $w$, although this is never explicitly discussed. In addition, models are tuned for only a few parameters for which abundant observations or reliable reanalysis data are available (e.g. pressure, temperature). There is no reason to assume that other parameters require the same weighting function, as these models are non-linear.

Hence we argue that $w$ is fundamentally unknown (and may actually vary with time and location). To conduct our analysis, we therefore assumed three different weighting functions and performed sensitivity studies (to be described later). The weighting function most used in this paper is a constant value throughout the grid box. This corresponds to the mental model that many scientists have of the physics processes that occur in a grid box. The other two weighting functions favour the area near the grid point more than the outer edges of the grid box. One weighting function uses a linear profile (highest at the grid point, zero at the edge) and another uses a Dirac- $\delta$ (centred at the grid point). The latter we consider a rather unlikely choice of $w$ but it does correspond to the case where the model has numerically converged.

\subsection{Some conventions used in this paper}

This paper contains many figures and statistics of spatial sampling error distributions. Instead of repeating the same information, some aspects are explained here. Error distributions are always given for either instantaneous ("hourly") or monthly data over a single region; see Table 1 . These error distributions are quantified through root-mean-square (RMS) values or quantiles. They represent typical errors per region (over no more than a month), which should not be mistaken
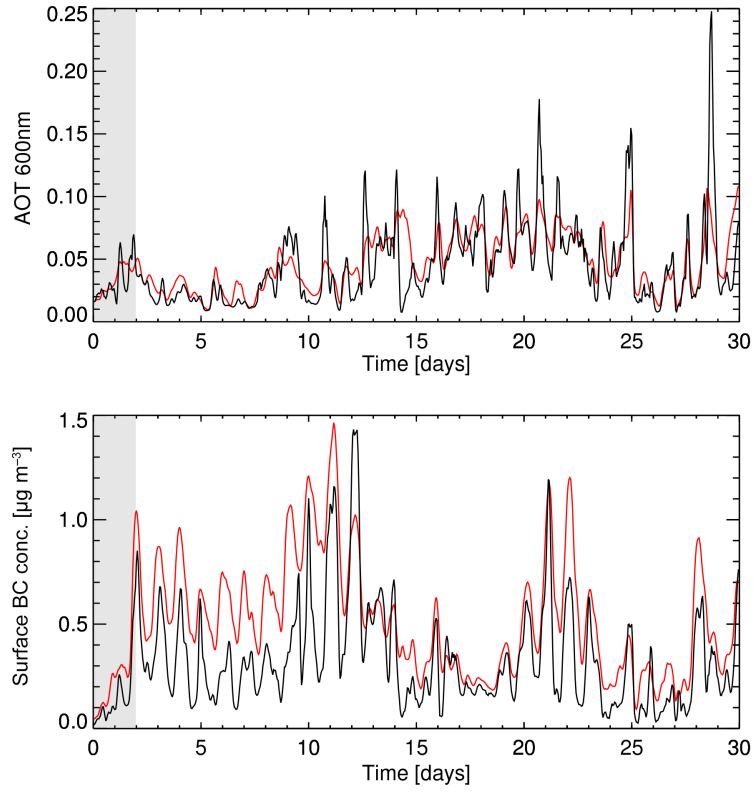

Figure 3. Time series of global model (red) and observed (black) AOT and surface black carbon concentration as simulated at a location south of Calais (France) by WRF-Chem MADE; see also Fig. 2. The grey area to the left shows the model's spin-up period.

for the typical error in any one longitude/latitude location. We use the so-called parametric seven-number summary of the $2,9,25,75,91$ and $98 \%$ quantiles $q$ of the errors because for a normal distribution, these quantiles are equally spaced. Any skewness or extended wings in a distribution will be readily visible. In particular, we often refer to the interquantile ranges $\Delta q_{50}=q_{75}-q_{25}, \Delta q_{82}=q_{91}-q_{9}$ and $\Delta q_{96}=q_{98}-q_{2}$. In e.g. Fig. 5, different shades of grey are used to denote these interquantile ranges: light grey for $\Delta q_{96}$, medium grey for the $\Delta q_{82}$ and dark grey for $\Delta q_{50}$. The solid blue line represents the median error. In Fig. 6, box-andwhisker plots show the error distributions. Different widths of the bars are used to denote different interquantile ranges: 

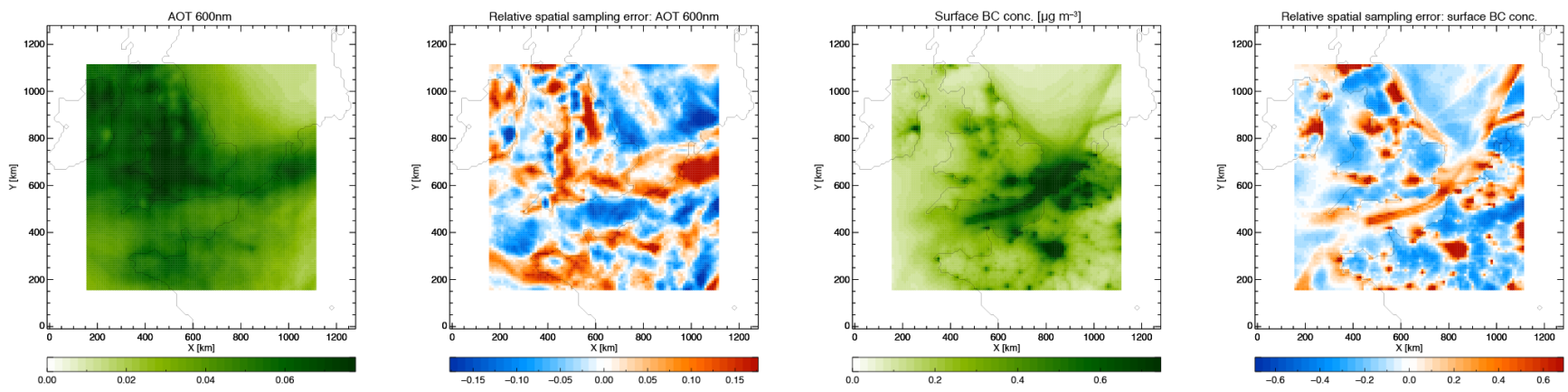

Figure 4. Monthly average of the simulated field and the relative spatial sampling error in the observation of AOT and surface black carbon concentration, as simulated over W. Europe by WRF-Chem MADE. Note that the high-resolution simulations encompass the whole region shown, while our analysis is only made for the coloured domain.

narrow for $\Delta q_{96}$, medium for $\Delta q_{82}$ and wide for $\Delta q_{50}$. The black rectangle represents the median error and the black circle the mean error. In a few figures, additional error distributions are shown using coloured lines: the $\Delta q_{50}, \Delta q_{82}$ and $\Delta q_{96}$ ranges will be indicated by solid, dashed and dotted lines, respectively.

The standard measure of uncertainty, the standard deviation, is half the $q_{84.1}-q_{15.9}$ interquantile range. For a Gaussian distribution, $\Delta q_{50}$ is 1.35 times the standard deviation, and $\Delta q_{82}$ is 2.68 times the standard deviation. For a Gaussian distribution with zero mean, the standard deviation and the RMS value will of course agree.

\section{Examples of spatial sampling errors}

In Fig. 2, we show instantaneous simulated AOT and surface black carbon concentration after 10 days in the WRF-Chem W. Europe run. By comparing the field in a small $10 \times 10 \mathrm{~km}$ box to the average of a large $210 \times 210 \mathrm{~km}$ box surrounding it (approximate size of present-day global model grid box), we assess spatial sampling errors. The centre of the large box we refer to as grid point (of the global model). By moving these two boxes together throughout the region, we can build up statistics of spatial sampling errors (also shown in Fig. 2). These errors can reach $\sim 100 \%$ and form coherent patterns several global model grid boxes large. Time series of the global model and observed values at a single location are shown in Fig. 3. In the case of AOT, we see that the perfect observation can both over- and underestimate the perfect model value with variations on a timescale of a day or so. The black carbon time series, on the other hand, shows systematic underestimation by the perfect observation over long periods for most of the month (note that events of overestimation also occur but on smaller timescales). Although these time series vary a lot throughout the region, this example is nevertheless typical. A video of the W-Europe simulation of AOT and surface black carbon mass concentrations can be found at http://dx.doi.org/10.5446/18550.
Since these spatial sampling errors are substantial, it makes sense to try and reduce them by temporally averaging the data. In Fig. 4, we show monthly averaged simulated AOT and surface black carbon concentration from the same run. The spatial sampling errors in monthly averaged observations are also shown in Fig. 4. They are smaller than the errors for instantaneous fields but are still quite substantial (up to $\sim 20 \%$ for AOT and $\sim 65 \%$ for black carbon). Note also that the error patterns have become larger and more coherent. As a matter of fact, notice how closely the patterns in sampling errors for black carbon agree with its emission sources, except that sampling errors are negative (and quite large) where concentrations are quite low. When defining areas downstream from sources where the aerosol is supposedly well-mixed spatially, it is important to consider the gridbox size of the model which is evaluated as much as the length scales involved in the actual aerosol processes.

The effectiveness of temporal averaging is shown in Fig. 5, where the spatial sampling errors are shown as a function of averaging period. Temporal averaging does decrease spatial sampling errors but not as fast as one would expect if instantaneous sampling errors behaved like independent Gaussian noise. This is understandable because the persistence of emission sources and flow patterns in the atmosphere create temporal correlations in the fields of a few hours to a few days. Note that AOT is more strongly (beneficially) affected by temporal averaging than surface black carbon concentrations.

\section{Agreement among models}

Before studying these spatial sampling errors in more detail, we consider how (dis)similar they are among different models. The Europe region simulated by EMEP encompasses the W. Europe region simulated by WRF-Chem MADE and so these two models allow ready intercomparison for May 2008; see Fig. 6. We see that both instantaneous and monthly errors as predicted by WRF-Chem and EMEP are of similar magni- 

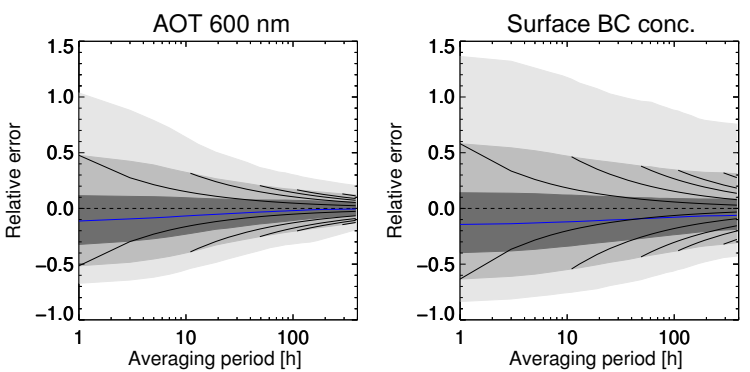

Figure 5. Relative spatial sampling error as a function of averaging period. The thin black lines are prognosis of the 9 and $91 \%$ quantiles in case these errors behaved like independent Gaussian errors (i.e. $1 / \sqrt{n}$, with $n$ the number of observations). Results from WRFChem MADE over W. Europe. Further explanation in Sect. 3.2.

tude although WRF-Chem generally produces larger errors. Error magnitudes for different observables behave similarly among WRF-Chem and EMEP: monthly errors for AOT and surface black carbon are the smallest and largest errors, respectively. EMEP monthly error maps (see Fig. 7) also look similar to WRF-Chem results (Fig. 4), especially for black carbon surface concentrations.

It would be interesting to understand the reason for the differences. From global model studies in the context of AEROCOM (e.g. Myhre et al., 2013; Randles et al., 2013; Stier et al., 2013), we know that such attribution is difficult and here we limit ourselves to pointing out some obvious differences between WRF-Chem and EMEP. First, there are differences in emission inventories and sea-salt emission parametrisations. Second, although both models were nudged to reanalysis data, transport will be different due to different dynamical cores and vertical resolution (WRFChem uses twice the vertical resolution as EMEP). For similar reasons wet and dry deposition are different. Both models also use a very different aerosol scheme (bulk mass or twomoment scheme). All of this will affect aerosol lifetimes, which in turn will affect the spatio-temporal variability of aerosol.

It should also be pointed out that EMEP shows quite a bit of month-to-month variation: e.g. January 2008 errors for AOT and March 2008 errors for surface black carbon concentration are markedly bigger than those estimated for May.

The most important point here is that both models suggest spatial sampling errors of similar magnitude with similar spatial patterns.

\section{Different observables and different regions}

Figure 8 shows relative spatial sampling errors (either instantaneous or monthly) for all observables and the three WRFChem MADE regions (see also Table 1 and Fig. 1). Instantaneous RMS errors are large: from $20 \%$ up to $160 \%$ depending on observable and region (the RMS errors are calculated
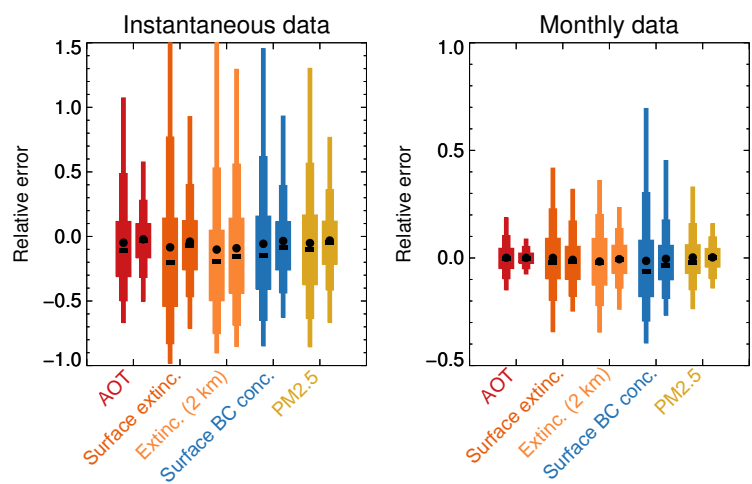

Figure 6. Relative spatial sampling errors (for either instantaneous or monthly data; note the different vertical axes) over the W. Europe region as calculated by WRF-Chem MADE (left bar) and EMEP (right bar) in May 2008. Further explanation in Sect. 3.2.

over a single region for the full month, see Table 1). There are clear and (mostly) systematic differences among the three regions in that W. Europe shows the largest errors and Congo the smallest. This may be related to the overall wind flow; Congo shows the most laminar flow (and hence most coherent aerosol plumes), while W. Europe shows a very turbulent flow (we do not wish to discount other effects like the spatio-temporal distribution of sources but a full explanation is beyond this paper's scope). Two observables (black carbon concentrations near $2 \mathrm{~km}$ a.g.l. for all three regions and surface CCN at $S=0.02 \%$ in W. Europe) show errors down to $-100 \%$. In the case of black carbon, this is due to narrow black carbon plumes travelling through an otherwise pristine air layer; the observation often sees the pristine air but the model always includes contributions from the plume. In the case of CCN, the background $\mathrm{CCN}$ at $S=0.02 \%$ is very low, especially close to sources where many small particles are emitted. However, once in a while a plume of larger particles travels over, giving rise to much larger $\mathrm{CCN}$ at low supersaturation $S=0.02 \%$.

The monthly errors can be reduced quite a bit compared to the instantaneous errors. For many observables, RMS errors are $5-15 \%$, although for observables like surface black carbon concentrations and N10 it can be $30-50$ and $30-80 \%$, respectively, with individual errors reaching over $100 \%$. Congo represents quite a different situation from the other two regions: the reduction due to averaging is much less, and in the case of surface N10 there is actually a slight increase in errors. An important difference between W. Europe and Oklahoma on the one hand and Congo on the other is that the first have mostly fixed aerosol sources with a prescribed diurnal cycle. The latter has emission sources (fires) in different locations from day to day.

Figure 9 shows relative spatial sampling errors for the other three regions, all simulated by models with bulk mass schemes for aerosol. In general, spatial sampling errors appear to be a bit smaller than in Fig. 8, but note the exception 

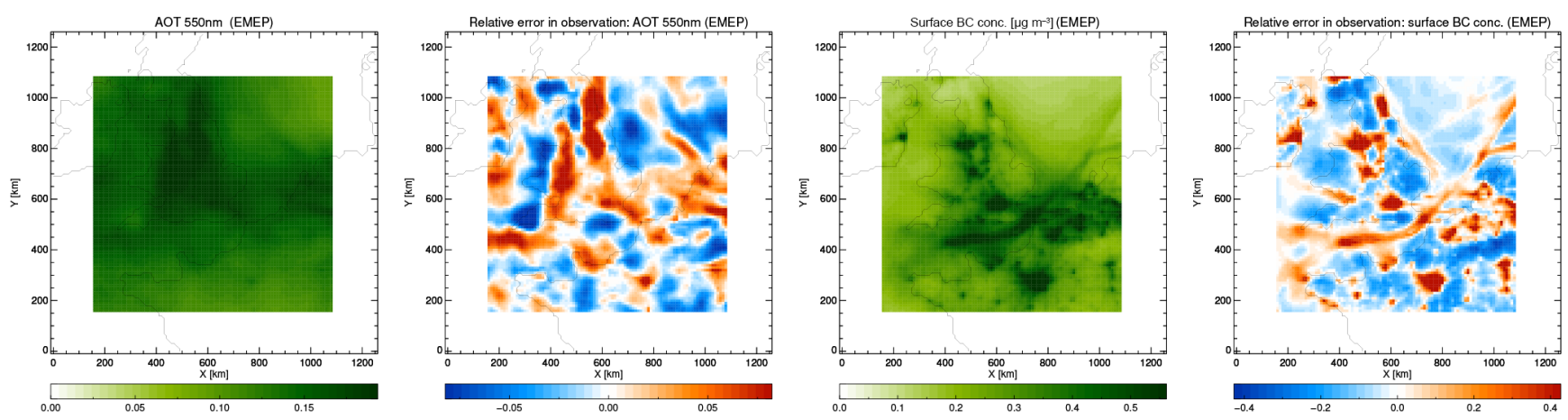

Figure 7. Monthly average of the simulated field and the relative spatial sampling error in the observation of AOT and surface black carbon concentration, as simulated over W. Europe by EMEP. This can be compared to results for WRF-Chem MADE as shown in Fig. 4 but note that the colour bars have different ranges to bring out spatial patterns better.

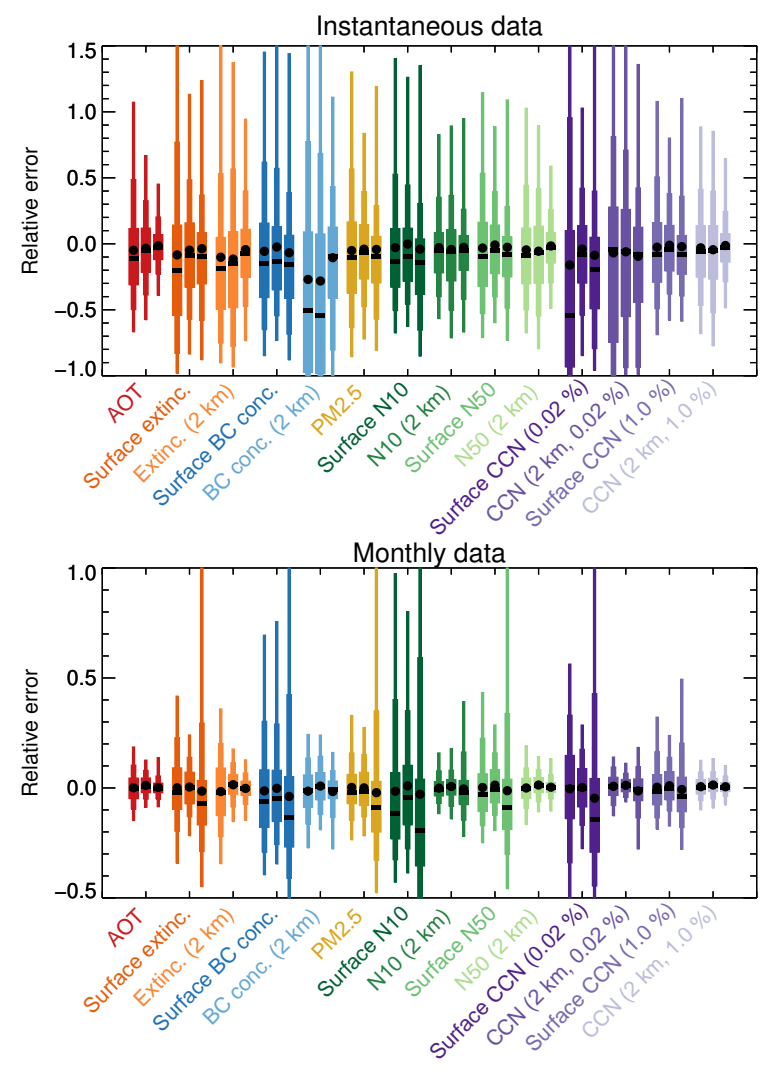

Figure 8. Relative spatial sampling errors (for either instantaneous or monthly data; note the different vertical axes) for all WRF-Chem MADE regions (left bar: W. Europe; centre bar: Oklahoma; right bar: Congo). Further explanation in Sect. 3.2.

of extinction near $2 \mathrm{~km}$ a.g.l. Monthly sampling errors over ocean are very low, due to spatial correlations in the nearsurface wind-speeds that cause sea-salt aerosol emission. However, large errors are found for extinction over ocean near $2 \mathrm{~km}$ a.g.l., that seem partly due to isolated plumes of sea salt but mostly due to a broken cloud field that rains out sea salt locally. Both instantaneous and monthly errors over
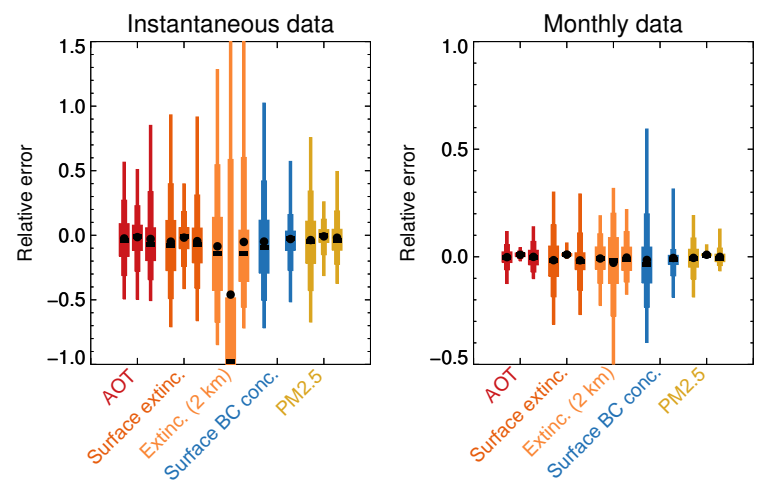

Figure 9. Relative spatial sampling errors (for either instantaneous or monthly data, note the different vertical axes) for three regions simulated with bulk mass schemes (left bar: Europe; middle bar: Ocean; right bar: Japan). Black carbon concentrations over the ocean are zero and so are related spatial sampling errors. Further explanation in Sect. 3.2.

Japan become larger if only observations over the land area are considered. The Japan region includes parts of the Japan Sea and the North Pacific Ocean that account for more than $80 \%$ of the simulated area. Additionally, the Japan simulation, like the Congo simulation, shows rather laminar flow from mesoscale to synoptic scale. Finally, simple statistics like in Fig. 9 cannot convey that over an extended region like Europe there are areas with systematically small or large sampling errors due to source locations and orography (see also Figs. 4 and 7).

In the case of actual observations, there may be quite a bit of intermittency in their temporal sampling, suggesting that the spatial sampling decreases we have shown here for monthly averages represent a best-case scenario. For a study of errors due to temporal sampling we refer to Schutgens et al. (2016). 

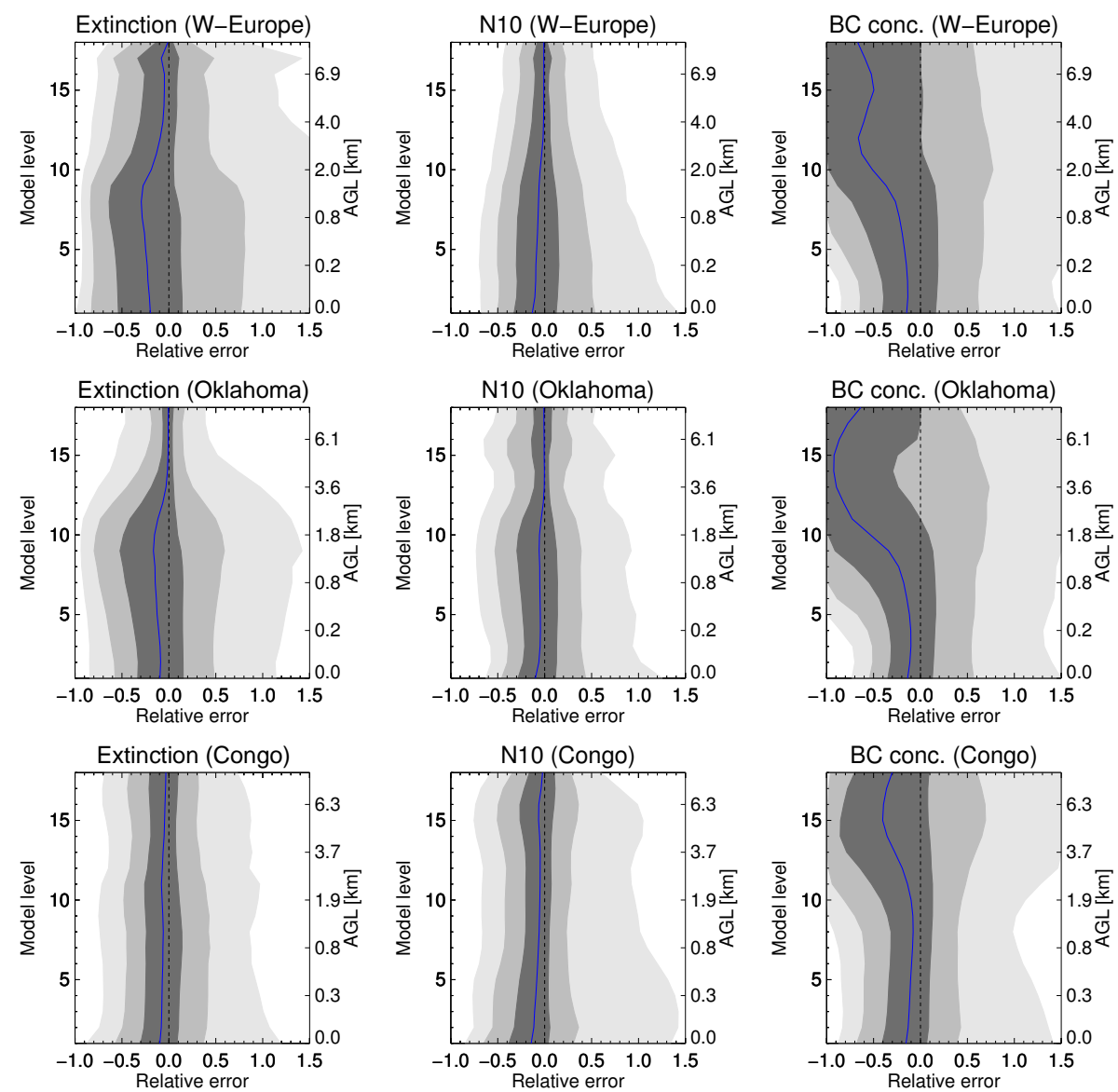

Figure 10. Relative spatial sampling error (instantaneous data) as a function of model level (left vertical axis) and altitude above ground level (a.g.l., right vertical axis) for extinction, N10 and black carbon concentrations. Results for the WRF-Chem MADE simulations. Further explanation in Sect. 3.2.

\section{Vertical distribution of sampling errors}

The vertical distribution of spatial sampling errors can be very different depending on observable and region. Figures 10 and 11 show the instantaneous and monthly relative spatial sampling error profiles for extinction, N10 and black carbon concentrations.

We see that although errors are typically largest at and near the surface, this does not preclude large errors higher up in the atmosphere. The instantaneous errors for black carbon concentrations actually show largest errors from 2 to $7 \mathrm{~km}$ a.g.l. This is due to black carbon plumes in a relatively pristine background, which also explains why the error distribution is so clearly skewed to negative values (observation sees the pristine background while the model also includes plumes). Black carbon's only source is surface emission, but both extinction and N10 also have sources throughout the troposphere (nucleation, condensation and in-cloud production of sulfate) which likely explains the difference between these observables.
For the monthly errors, most profiles show secondary maxima in sampling errors well above the surface.

We have analysed the sampling errors at their original model levels, which for these simulations occur at fairly constant altitude above ground. Note that the errors estimated in this subsection do not take into account that a global model's grid box may have a vertical extent larger than that of our regional simulations. Taking this into account would only increase the estimated errors. The profiles of spatial sampling errors for the bulk mass simulations are rather constant and therefore not discussed here.

\section{Impact of grid-box size and shape}

\subsection{Impact of latitude}

Although our high-resolution simulations were made at different latitudes on Earth, so far we have assumed that the global model grid-box size is equal to the grid-box size of a T63 grid at the equator $(210$ by $210 \mathrm{~km})$. At higher latitudes, the longitudinal extent of the grid box shrinks (at least 

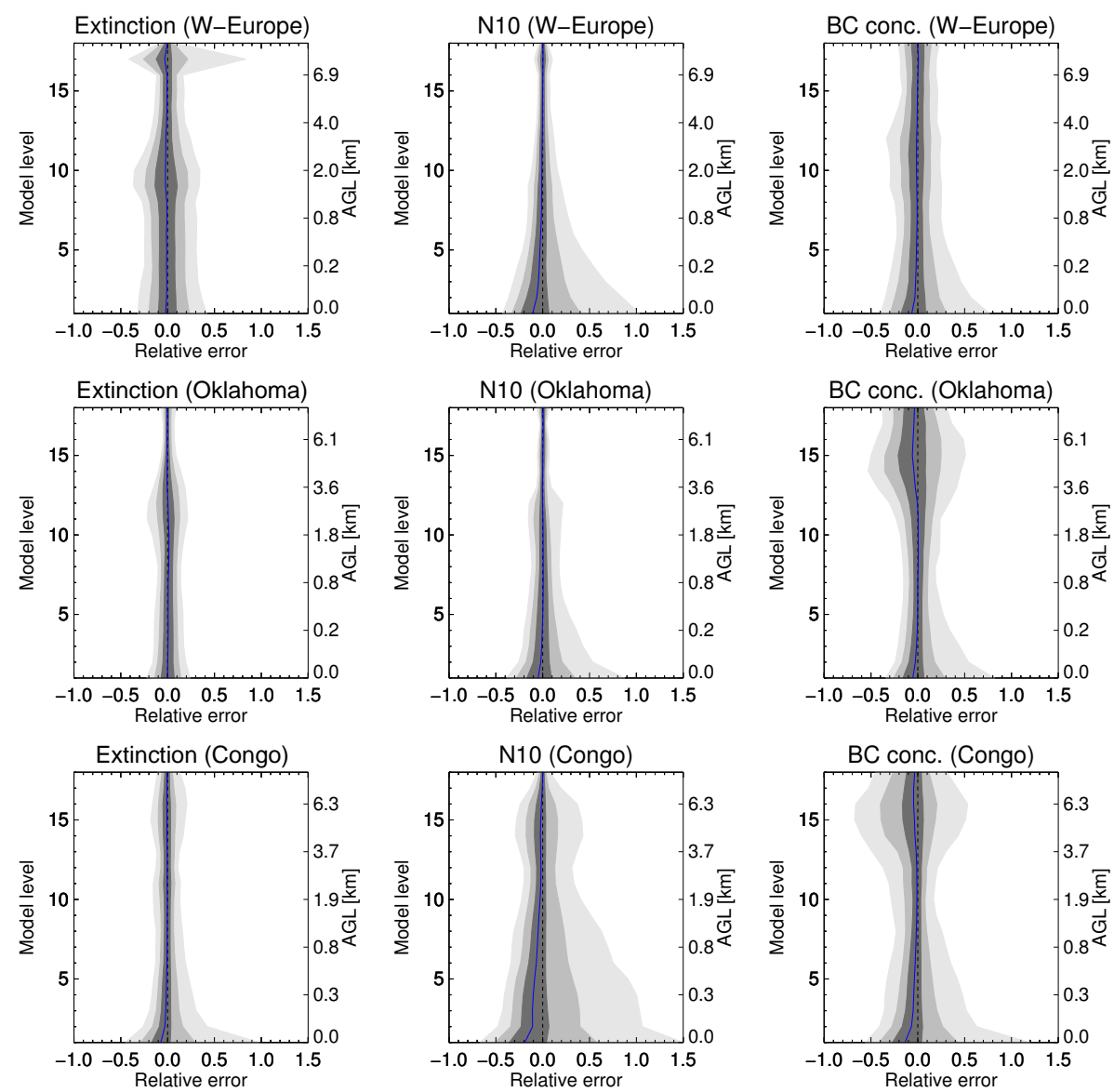

Figure 11. Relative spatial sampling error (monthly data) as a function of model level (left vertical axis) and altitude above ground level (a.g.l., right vertical axis) for extinction, N10 and black carbon concentrations. Results for the WRF-Chem MADE simulations. Further explanation in Sect. 3.2.

for rectangular grids), which may reduce spatial sampling errors. This is explored in Fig. 12. As we can see, smaller longitudinal extent leads to smaller errors although the effect is rather mild. When the longitudinal extent is halved, errors in monthly averaged fields decrease between 10 and $30 \%$ of the original errors, with $\sim 20 \%$ a very typical value. Additionally, larger errors are usually less affected than smaller errors, although the differences are not very big. Spatial sampling errors in instantaneous fields behave very similarly (not shown), although fields that show very large errors (like surface BC or surface CCN at $S=0.02 \%$ ) tend to show less improvement $(\sim 10 \%)$ when the grid-box longitudinal extent is halved.

Note that the longitudinal extent only has an impact on spatial sampling errors because there are spatial and temporal correlations in the aerosol fields. If these fields were independent random noise, decreasing longitudinal extent would barely have an impact on sampling errors.
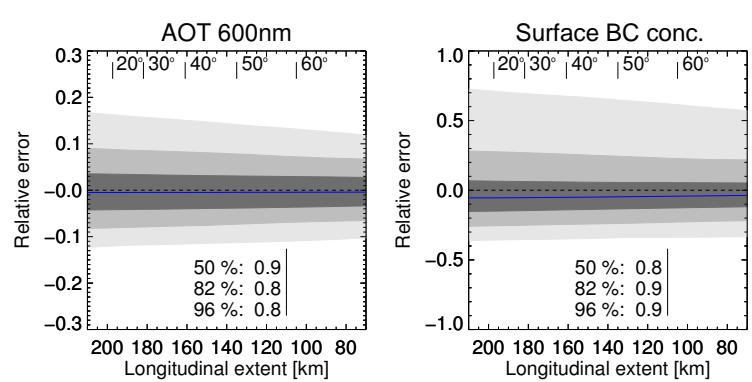

Figure 12. Relative spatial sampling errors (monthly data) as a function of longitudinal extent of the grid box (due to latitude). Near the top horizontal axis, latitudes are given. Near the bottom horizontal axis, the ratios of $\Delta q_{25}, \Delta q_{82}$ and $\Delta q_{96}$ at two different longitudinal extents ( 110 over $210 \mathrm{~km}$ ) are given. Results from WRF-Chem MADE over W. Europe. Further explanation in Sect. 3.2. 

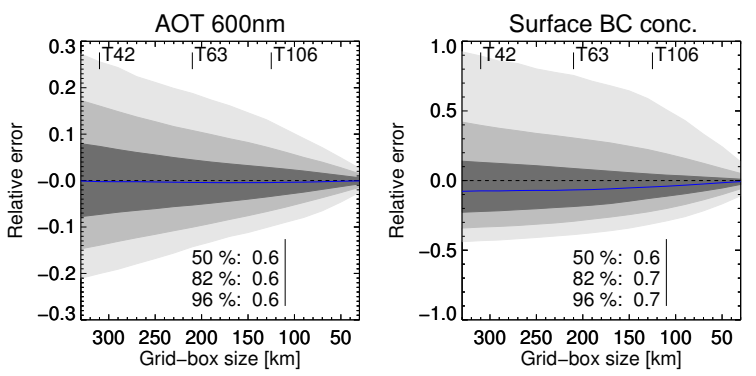

Figure 13. Relative spatial sampling errors (monthly data) as a function of grid-box size. Near the top horizontal axis, standard spectral grid sizes are shown. Near the bottom horizontal axis, the ratios of $\Delta q_{25}, \Delta q_{82}$ and $\Delta q_{96}$ at two different grid-box sizes (110 and $210 \mathrm{~km}$ ) are given. Results from WRF-Chem MADE over W. Europe. Further explanation in Sect. 3.2.

\subsection{Impact of grid-box size}

The impact of model resolution is also easily explored; see Fig. 13. Monthly sampling errors decrease by 10 to $50 \%$ from T63 (210 by $210 \mathrm{~km})$ to T106 (125 by $125 \mathrm{~km}$, a third of the T63 grid-box area), with $40 \%$ a rather typical value. Surface observations are less affected with decreases of $\sim 30 \%$, especially N10 whose spatial sampling errors in all three simulations only decreased by $\sim 20 \%$ when the grid-box size was halved. For instantaneous values (not shown), the typical reduction in sampling error is smaller, $\sim 30 \%$, especially for surface fields, $\sim 20 \%$.

As with the longitudinal extent, grid-box size only has an impact because of the spatial and temporal correlations in the aerosol fields. A field of independent random noise exhibits sampling errors quite independently of grid-box size (unless the box, and the number of values therein, becomes very small).

\section{Observations offset from the grid point}

So far we have considered observations at the exact grid point of a global model's grid box which is a useful starting point but also quite unrealistic. For a sample of randomly distributed observations in a 210 by $210 \mathrm{~km}$ grid box, only $2 \%$ will be within $10 \mathrm{~km}$ of the grid point and $50 \%$ will be more than $84 \mathrm{~km}$ away from it. By considering observations located throughout the grid box, and not just its centre, it is possible to show how monthly sampling errors increase with distance of the observation to the grid point; see Fig. 14. As a matter of fact, $50 \%$ of possible AOT observations have errors at least twice as large as found for an observation at the grid point. Observations in the very corners of the grid box exhibit errors 3 times as large. The increase of sampling errors with distance to the grid point for surface black carbon concentrations is not as large but still significant.
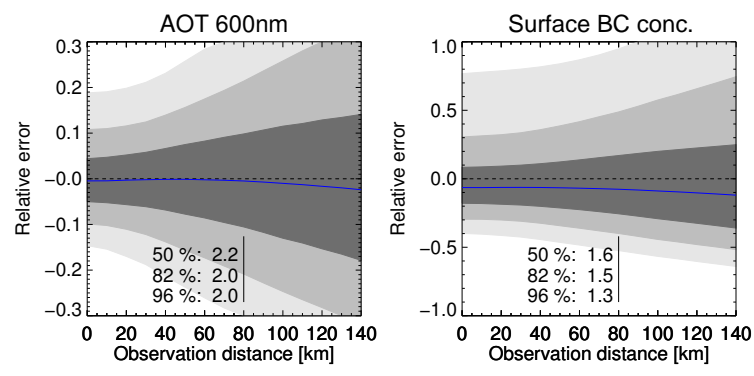

Figure 14. Relative spatial sampling error (monthly data) as a function of distance of the observation to the grid point. Near the bottom horizontal axis, the ratios of $\Delta q_{25}, \Delta q_{82}$ and $\Delta q_{96}$ at a distance of 80 and $0 \mathrm{~km}$ are given. Results from WRF-Chem MADE over W. Europe. Further explanation in Sect. 3.2.

That sampling errors increase with distance may be surprising but can be explained. The evolution of aerosol across a global model grid box may differ quite a bit due to differences in sources, flow and deposition (especially wet). Nevertheless, as is well known from observations, aerosol exhibits correlations over several tens of kilometres (Anderson et al., 2003; Kovacs, 2006; Santese et al., 2007; Shinozuka and Redemann, 2011; Schutgens et al., 2013) and our highresolution simulations are no different. Hence, an observation at the centre of a grid box will correlate strongly with a large part of that grid box, while an observation in the upperright corner will only correlate strongly with (part of) the upper-right quadrant of that grid box but less so with the lower-left quadrant. It is important to realise that aerosol in individual $10 \times 10 \mathrm{~km}^{2}$ boxes cannot be considered as independent and identically distributed (i.i.d.) random variables. If aerosol behaved like i.i.d. random variables, sampling errors would not increase with distance.

Figure 15 shows box-and-whisker plots of monthly sampling errors for several observables, either at the grid point, or at a distance of 70 or $100 \mathrm{~km}$, for the W. Europe region. Similar results can be shown for Oklahoma and Congo, where the relative increase with distance is often (but not always) larger. For all three regions and all observables, the increase for $\Delta q_{82}$ at $70 \mathrm{~km}$ is between 1.2 and $2.3 \times$ and the increase at $100 \mathrm{~km}$ is between 1.4 and $3.4 \times$. Instantaneous spatial sampling errors increase less fast with distance but still significantly; typical increases for $\Delta q_{82}$ at $70 \mathrm{~km}$ is 1.3 for AOT and 1.2 for surface black carbon concentration (i.e. monthly averaging is more beneficial for an observation at the grid point than one at $70 \mathrm{~km}$ distance).

As discussed before (Sect. 3.1), the meaning of a global model's grid-point value is not obvious. So far we have assumed that the grid-point value is the unweighted average of the high-resolution field over the global model's grid box (i.e. a constant weighting function $w$ ). Here, we explore how the sampling errors depend on different weighting functions. Figure 16 shows how a constant, linear or Dirac- $\delta$ weighting function affects sampling errors as a function of distance 


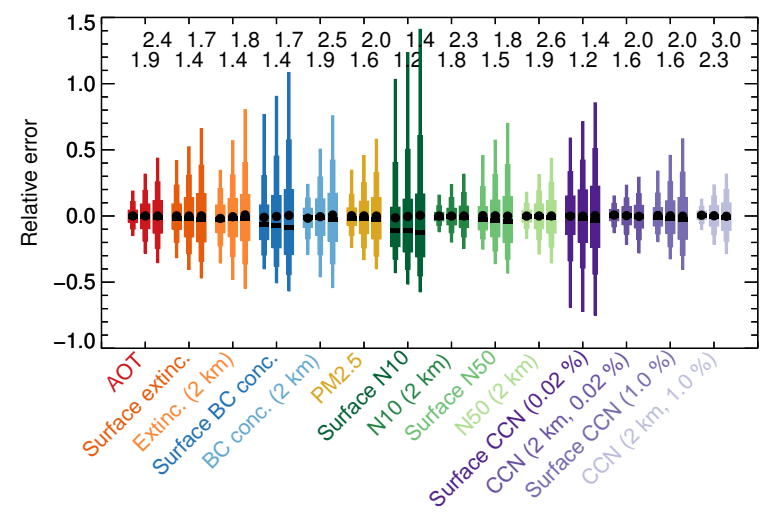

Figure 15. Relative spatial sampling error (monthly data) as a function of distance of the observation to the grid point. The numbers near the top horizontal axis show the increase of $\Delta q_{82}$ at 70 and $100 \mathrm{~km}$ relative to $0 \mathrm{~km}$. Results from WRF-Chem MADE over W. Europe. Further explanation in Sect. 3.2.

to the grid point. For the Dirac- $\delta$ weighting function, sampling errors are equal to zero at a distance of zero: the global model's value is equal to the observation (since both are perfect). However, as distance increases, so will the spatial sampling errors. Actually, for distances larger than $\sim 30 \mathrm{~km}$, the three very different weighting functions give rather similar sampling errors (but notice that more localised weighting functions yield larger errors as expected). Since for randomly distributed observations, only $\sim 6 \%$ would be closer than $30 \mathrm{~km}$ to the grid point, we feel it is justified to conclude that the shape of the weighting function only has a small impact on statistics of spatial sampling errors. The spatio-temporal variation of the field is far more important.

\section{Strategies for reducing sampling errors}

The typical sampling errors when the observation is at the model grid point are lower than those for an observation offset from the grid point. It seems unlikely that we can devise strategies to reduce centre-of-grid-box errors, other than temporal averaging (see Sect. 6) or further averaging global model data (and their associated observations) over multiple grid boxes. However, the sampling errors for observations offset from a grid point might be reduced by proper screening, interpolation within the model grid or considering multiple observations at the same time.

\subsection{Observations close to the model grid point}

As Fig. 14 shows, the smallest spatial sampling errors occur for observations close to the model grid point. As a matter of fact, within a distance of $30 \mathrm{~km}$, there is hardly any change in the errors (note: this figure uses the constant weighting function). To keep sampling errors as small as possible, one might only select observations that are within
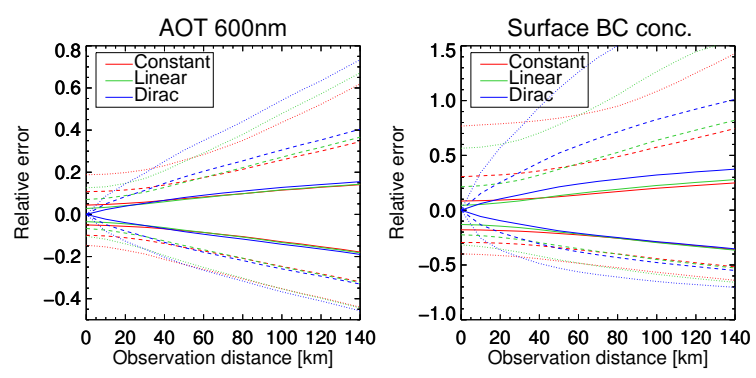

Figure 16. Relative spatial sampling error (monthly data) as a function of distance of the observation to the grid point, for three different weighting functions. Results from WRF-Chem MADE over W. Europe. The usual interquantile ranges $\Delta q_{50}$ (solid), $\Delta q_{82}$ (dashed) and $\Delta q_{96}$ (dotted) are shown.

$30 \mathrm{~km}$ of a model grid point. A T63 grid box at the equator $\left(210 \times 210=44100 \mathrm{~km}^{2}\right)$ implies that only $6 \%$ of randomly distributed observations would be usable, a substantial reduction of potential observational data. For an upper distance of $50 \mathrm{~km}$, this increases to $18 \%$ of observations, still representing a significant loss of observational data.

One benefit of selecting only observations close to the grid point is that here the impact of the weighting function is most pronounced (see also Fig. 16); so within $30 \mathrm{~km}$ of the grid point, spatial sampling errors may actually be very small if the weighting function is highly localised. Since it is impossible to know the actual weighting function, it may be difficult to assess whether it is localised or not.

\subsection{Aggregating observations over the model grid box}

It has been suggested (e.g. Sayer et al., 2010) that aggregating observations over a model grid box is the best strategy for comparing models with observations. Obviously, such a strategy is only possible for satellite data that provide contiguous wide swath observations (e.g. MODIS, MISR, POLDER, SEVIRI). Moreover, it can be expected that the success of this strategy depends on the weighting function that is applicable. Figure 17 shows relative spatial sampling errors in case of observations that are spatially aggregated before comparison to the model (it is assumed the aggregation is space-filling). Here the model grid point and the centre of the aggregated observations coincide. As a result, sampling errors go to zero for the constant weighting function as the observational aggregation approaches the extent of the grid box. For the linear weighting function, we see that errors initially become smaller as the aggregation increases and then grow again as the observational aggregation approaches the extent of the grid box. Still, sampling errors are halved when aggregating observations over the full grid box so there is clearly a benefit. The extreme weighting function of the Dirac- $\delta$ obviously leads to large errors.

For actual satellite measurements it will be difficult to observe the complete grid box, due to e.g. cloud cover, sun 

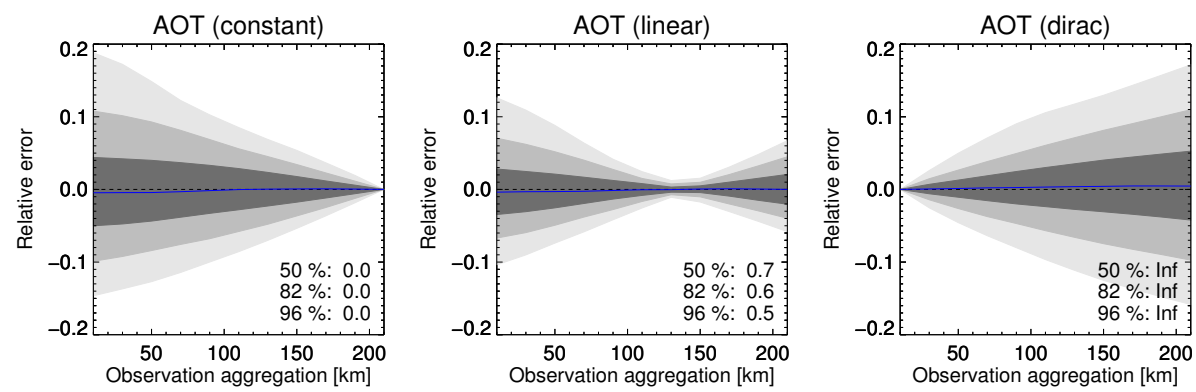

Figure 17. Relative spatial sampling error (monthly data) as a function of aggregation extent of the AOT observations, using three different weighting functions. The centre of the aggregated observations is assumed to coincide with the model's grid points. In the lower right corner, the ratios of $\Delta q_{25}, \Delta q_{82}$ and $\Delta q_{96}$ at two different aggregation extents (210 to $0 \mathrm{~km}$ ) are given. Results from WRF-Chem MADE over W. Europe. Further explanation in Sect. 3.2.
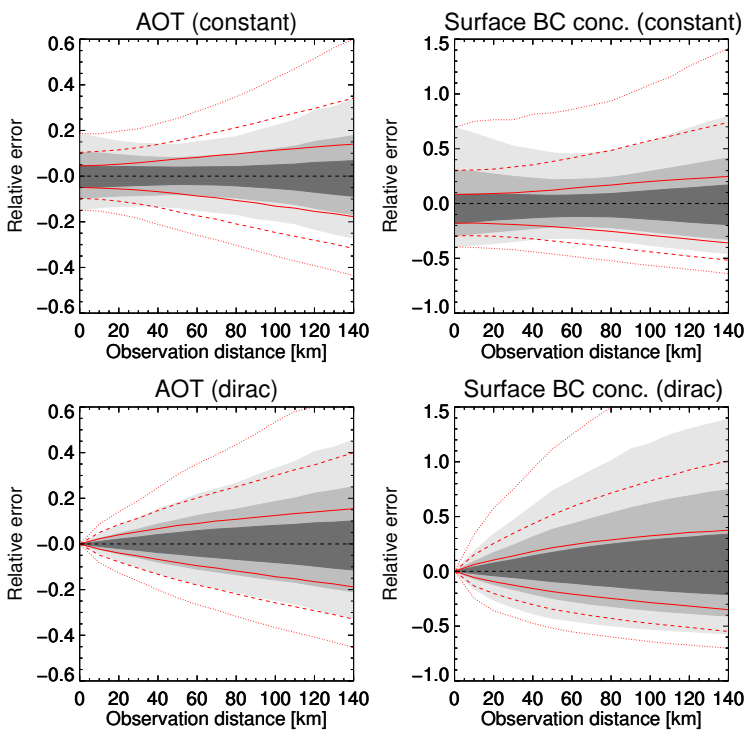

Figure 18. Relative spatial sampling error (monthly data) for four randomly distributed sites as a function of distance to the grid point, assuming two different weighting functions. The red lines indicate the errors for a single site (see also Fig. 14). Results from WRFChem MADE over W. Europe. Further explanation in Sect. 3.2.

glint or high surface albedo. Sayer et al. (2010) show that in the case of Advanced Along Track Scanning Radiometer (AATSR) observations (nominal $10 \times 10 \mathrm{~km}$ pixel) and the GEOS-Chem model $\left(5^{\circ} \times 4^{\circ}\right.$ grid box $)$ it is extremely unlikely that more than $50 \%$ of a model grid box would be covered by observations; that is, space-filling aggregations over global model grid boxes are very unlikely.

\subsection{Multiple observations in a model grid box}

Instead of a space-filling aggregation, one could average multiple observations in the same grid box before comparison to the grid point value and hopefully reduce sampling errors. The idea here is that if the observations are sufficiently
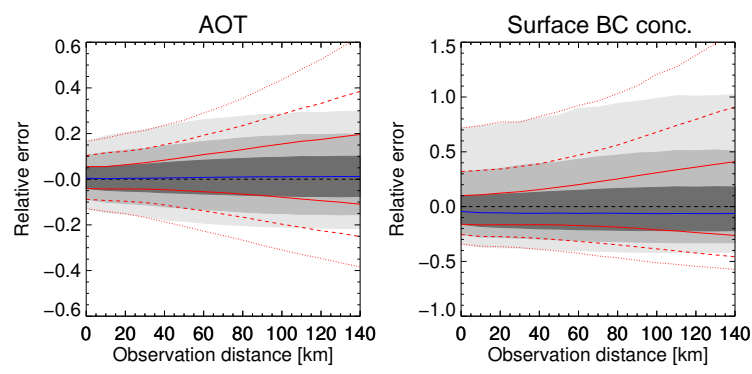

Figure 19. Relative spatial sampling error (monthly data) in case of linear interpolation of model values to the observation, as a function of distance to the grid point. The red lines indicate the errors without interpolation (see also Fig. 14). Results from WRF-Chem MADE over W. Europe. Further explanation in Sect. 3.2.

far apart and represent fairly independent samplings of the field within the grid box, their average should be distributed closer to the (weighted) grid-box average than an individual observation. This is similar to the previous subsection, except far fewer observations are needed and no space-filling aggregation is required. This strategy may be employed for surface sites as well as for satellite data.

Figure 18 show errors in case of four independently distributed observations throughout the grid box. Clearly, averaging multiple observations helps to reduce spatial sampling errors, even when the Dirac- $\delta$ weighting function is assumed! However, note that this improvement is less in case of more localised weighting functions. For the constant weighting function, we also see that smallest errors now occur not at a distance of $0 \mathrm{~km}$, but at a distance of 50 to $70 \mathrm{~km}$ (for the linear weighting function this minimum shifts closer to the grid point). This is quite understandable; close to the grid point, multiple observations are clustered together. Hence they will not be very different. As distance increases, the randomly distributed observations sample more of the grid box. Obviously, using more observations than four will give better results (not shown). 

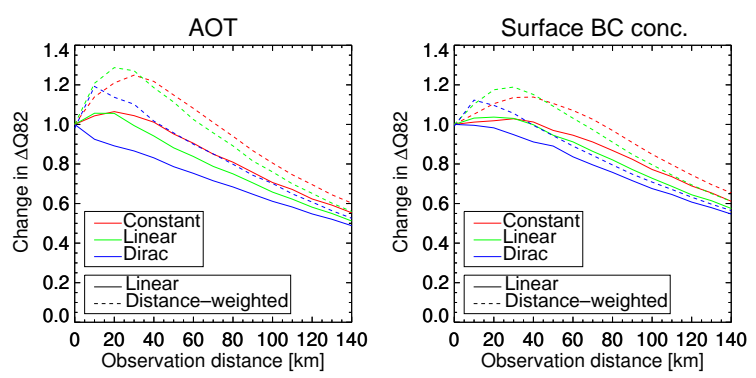

Figure 20. Change (relative to Fig. 14) in $\Delta q_{82}$ (for monthly relative sampling errors) due to interpolation, as a function of distance to the grid point. All three weighting functions and two interpolation methods are considered. Similar graphs for $\Delta q_{50}$ and $\Delta q_{96}$ can be shown.

Note that Fig. 18 does not suggest that any set of four observations reduces sampling errors; if those observations are very close together, averaging them will hardly improve on the error.

\subsection{Interpolating model data among grid points}

By interpolating the model data to the location of an observation, it may be possible to reduce spatial sampling errors for observations located away from the model grid point. The idea is to construct virtual model data for a virtual grid box centred on the observation. This interpolation can be performed in different ways; here we consider linear interpolation and distance-weighted averaging. Figure 19 shows that linear interpolation in case of a constant weighting function clearly has a beneficial effect on spatial sampling errors, especially for observations far from the global model's grid point. Notice that from about $80 \mathrm{~km}$ distance, errors become constant and no longer increase with distance (they are always larger than the errors for an observation at the grid point). Obviously, the impact depends on the weighting function and interpolation method, as shown in Fig. 20. Figure 20 shows that interpolation is most beneficial for observations farthest from the grid point and can actually lead to larger errors close to the grid point (especially for distant-weighted averaging). Interestingly, the more localised the weighting function, the more beneficial the interpolation (presumably because the global model data are now identical to observations at the grid point). Finally, this figure shows that linear interpolation performs better than distance-weighted average. This holds for all observables and all regions we considered.

Much the same conclusions can be stated for instantaneous values, except that the beneficial impact of interpolation is less pronounced.

\section{Flight campaigns}

Unlike satellite or ground-site observations, measurements taken during a flight campaign cannot be properly averaged over time (at least on timescales from days to months and longer). To simulate the (nearly) instantaneous measurements during horizontal legs of flight campaigns, we use narrow tracks: $10 \mathrm{~km}$ wide and $210 \mathrm{~km}$ long, centred on the grid point and running in either east-west or north-south direction. Profiles of spatial sampling errors for such flight campaign data can be seen in Fig. 21. Compared to instantaneous point observations (also shown), the flight campaign observations are less affected by spatial sampling issues because they sample a larger part of the grid box. Even so, significant instantaneous RMS errors exist, varying between 10 and $41 \%$ for extinction, 10 and $46 \%$ for N10 and 21 and $100 \%$ for black carbon concentrations at different altitudes and for different regions (these errors are for a best-case scenario: a grid-box long flight path centred on the grid point). For Congo, spatial sampling errors can be quite different depending on whether the flight path runs north-south or eastwest around $6 \mathrm{~km}$ a.g.l. Prevailing wind flows are east-west, resulting in similarly orientated plumes. If the flight track observations are within and along such a plume, spatial sampling errors will be large and positively biased. If the flight track observations are across such a plume, errors will be smaller and (over a large domain) unbiased.

The Congo results highlight a particular issue with flight campaign data: if the flight tracks have deliberately been chosen to follow observed aerosol plumes, perfect observations will overestimate perfect model values by significant amounts.

Almost vertical legs of flight campaigns should experience errors like those discussed for point observations, Sect. 7. Notice that we do not consider the vertical extent of a global model's grid box in our analysis.

\section{Conclusions}

The spatial resolutions of current global aerosol models and the observations used to evaluate them are very different. Model grid-point values are representative of areas of $\sim 200 \times 200 \mathrm{~km}^{2}$ but individual observations seldom see more than $\sim 10 \times 10 \mathrm{~km}^{2}$ of the atmosphere. This difference in the field of view should affect the evaluation of models with observations but has received little attention in the literature. We believe our paper is the first systematic and qualitative study of the differences between a perfect model and perfect observations due to spatial sampling.

Using high-resolution simulations for six different regions by two different regional models and one global model, we show that spatial sampling errors can be substantial across a range of observables (AOT, extinction, $\mathrm{PM}_{2.5}$, black carbon concentrations, number concentrations and $\mathrm{CCN}$ ). These 

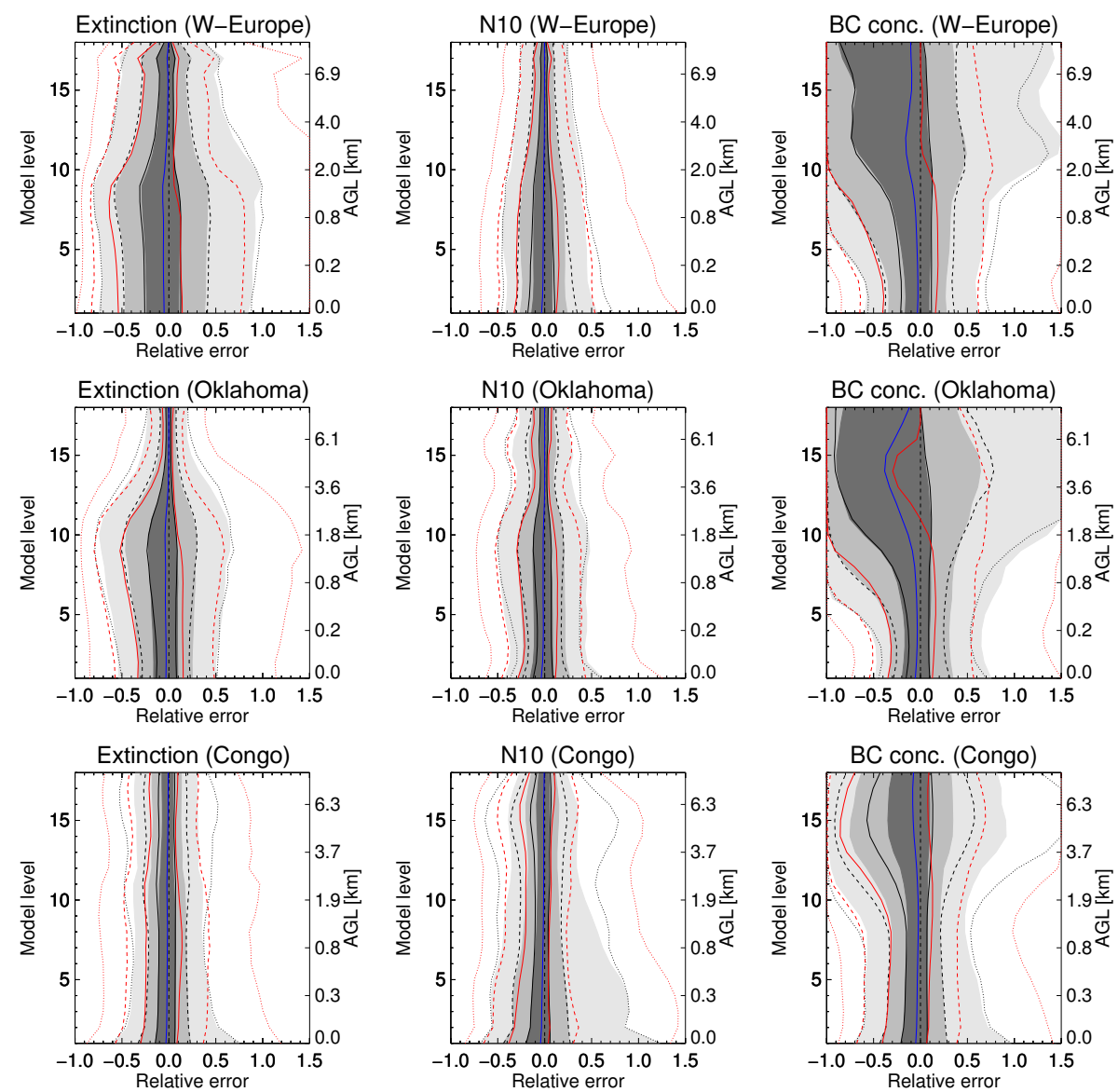

Figure 21. Relative spatial sampling error (for measurements during horizontal legs of a flight campaign) as a function of model level (left vertical axis) and altitude above ground level (a.g.l., right vertical axis) for extinction, N10 and black carbon concentrations. The grey shaded error ranges are for north-south flights. Similar error ranges for east-west flights are shown in black lines. The results of Fig. 10 are also shown in red lines. The usual interquantile ranges $\Delta q_{50}$ (solid), $\Delta q_{82}$ (dashed) and $\Delta q_{96}$ (dotted) are shown. Further explanation in Sect. 3.2 .

spatial sampling errors fluctuate in time and space, depending on emission sources, grid locations, weather and aerosol processes. Ultimately, they constitute noise that will be present in any model evaluation and that can not be eliminated entirely unless model grid sizes become smaller than observational fields of view.

Assuming observations that do not coincide with the global model's grid point but are offset by $80 \mathrm{~km}(54 \%$ of randomly located observations in a $210 \times 210 \mathrm{~km}$ grid box will be further away), the following statistics are offered. For instantaneous data, RMS spatial sampling errors (defined as observation minus global model value) are larger than $30 \%$, typically between 40 and $80 \%$ and may go up to $160 \%$ (depending on observable and region). These errors are typically positively skewed and highly non-Gaussian. For monthly data, RMS sampling errors are larger than $10 \%$, typically between 10 and $40 \%$ and may go up to $75 \%$ (depending on observable and region).

This noise can however be reduced; we have explored the impact of spatial or temporal averaging of data as well as selection of observations based on distance to a grid point or interpolation of model data to the location of an observation. Our study suggests that while increased model resolution will of course be beneficial, resolutions will need to be 4 times higher $\left(50 \times 50 \mathrm{~km}^{2}\right.$ grid-box area) before spatial sampling errors become significantly smaller. In the mean time, we recommend that both model data and observations are spatio-temporally averaged to ensure best agreement. Here the model data must first be spatially interpolated to and temporally collocated with the observation. Optimal averaging procedures will depend on the spatio-temporal sampling of the observations, the characteristics of the observable and the requirements of the scientific community; so we offer no single prescription although the results in this paper provide some guidelines. Optimal strategies for evaluating models with observations need to receive more attention from researchers.

Our results suggest that caution is needed when using in situ measurements in global model evaluation. These measurements consistently led to larger spatial sampling errors 
than remote sensing measurements like AOT. For instance, monthly surface black carbon concentrations and number densities for our simulations have RMS spatial sampling errors of at least 30 and up to $80 \%$. Best-case scenarios for flight campaign data still allowed spatial sampling errors of $100 \%$ and typically the observation would underestimate the model.

Regarding the large sampling errors in case of black carbon, other species (e.g. sulfate, sea salt) were not explicitly analysed in this paper but show different results (not shown). Sulfate errors tend to be rather small, probably due to the multitude of sources and relatively long lifetimes. Sea salt, on the other hand, shows large and systematic monthly sampling errors along coastlines (unsurprisingly). Given the size of our global model's grid box, these errors extend quite far into land or over sea. The important point here is that sampling errors for species mass concentrations can be very different dependent on species, and hence have a big impact on the evaluation of a model's particle speciation.

It is likely that the spatial sampling errors estimated in this paper are underestimates. First, Qian et al. (2010) showed that model spatial variability over $75 \mathrm{~km}$ increased significantly (by 60 to $100 \%$ ) when model resolution changed from 15 to $3 \mathrm{~km}$. Our current high-resolution simulations have resolutions of $10 \mathrm{~km}$. Second, our high-resolution simulations do not resolve fine-scale structure below $10 \mathrm{~km}$ while many in situ measurements actually have fields of view on the order of millimetres to centimetres (e.g. particle inlets). Third, our models are more limited in the spatio-temporal variation of their emission sources than reality due to assumed and constant diurnal patterns in anthropogenic emissions. Finally, even high-resolution models will have to take a broad view of aerosol and describe average properties (e.g. mass and/or number densities) instead of modelling individual aerosols in all their variety.

On the other hand, it is possible that in areas far away from sources (e.g. the free troposphere over the remote ocean) aerosol has mixed sufficiently to strongly reduce spatial sampling errors (e.g. HIPPO measurements over the Pacific; see also Weigum et al., 2012). Our simulations do not really allow us to explore this scenario.

In the interest of comparing likes to likes, this paper does not consider that real observations may have very intermittent temporal sampling, nor does it consider the impact that precipitation may have on spatio-temporal variability of aerosol (Gryspeerdt et al., 2015, for example). These issues are the subject of further investigation.

Acknowledgements. This work was supported by the Natural Environmental Research Council grant no. NE/J024252/1 (Global Aerosol Synthesis And Science Project).

E. Gryspeerdt acknowledges funding from the European Research Council under the EU Seventh Framework Programme FP7306284 (“QUAERERE”). D. Goto was supported by the Global Environment Research Fund S-12 of the Ministry of the Environment
(MOE)/Japan, the Grant-in-Aid for Young Scientist B (grant number 26740010) of the Ministry of Education, Culture, Sports and Science and Technology (MEXT)/Japan and KAKENHI/Innovative Areas (grant number 24110002) of MEXT/Japan. P. Stier acknowledges funding from the European Research Council under the EU Seventh Framework Programme (FP7/2007-2013)/ERC grant agreement FP7-280025. Michael Schulz and Svetlana Tsyro acknowledge funding from the Norwegian Research Council under the KLIMAFORSK project, AeroCom-P3. Their work was supported by EMEP under UNECE.

The figures in this paper were prepared using David W. Fanning's Coyote Library for IDL. The authors thank two anonymous reviewers for useful comments that helped improve the manuscript.

Edited by: Y. Balkanski

\section{References}

Ackermann, I. J., Hass, H., Memmesheimer, M., Ebel, A., Binkowski, F. S., and Shankar, U. M. A.: MODAL AEROSOL DYNAMICS MODEL FOR EUROPE: DEVELOPMENT AND FIRST APPLICATIONS, Atmos. Environ., 32, 2981-2999, 1998.

Albrecht, B. A.: Aerosols, cloud microphysics, and fractional cloudiness, Science, 245, 1227-1230, 1989.

Anderson, T. E., Charlson, R. J., Winker, D. M., Ogren, J. A., and Holmen, K.: Mesoscale Variations of Tropospheric Aerosols, J. Atmos. Sci., 60, 119-136, 2003.

Angstrom, B. A.: Atmospheric turbidity, global illumination and planetary albedo of the earth, Tellus, XIV, 435-450, 1962.

Ballester, J., Burns, J. C., Cayan, D., Nakamura, Y., Uehara, R., and Rodó, X.: Kawasaki disease and ENSO-driven wind circulation, Geophys. Res. Lett., 40, 2284-2289, doi:10.1002/grl.50388, 2013.

Beelen, R., Raaschou-Nielsen, O., Stafoggia, M., Andersen, Z. J., Weinmayr, G., Hoffmann, B., Wolf, K., Samoli, E., Fischer, P., Nieuwenhuijsen, M., Vineis, P., Xun, W. W., Katsouyanni, K., Dimakopoulou, K., Oudin, A., Forsberg, B., Modig, L., Havulinna, A. S., Lanki, T., Turunen, A., Oftedal, B., Nystad, W., Nafstad, P., De Faire, U., Pedersen, N. L., Östenson, C.G., Fratiglioni, L., Penell, J., Korek, M., Pershagen, G., Eriksen, K. T., Overvad, K., Ellermann, T., Eeftens, M., Peeters, P. H., Meliefste, K., Wang, M., Bueno-de Mesquita, B., Sugiri, D., Krämer, U., Heinrich, J., de Hoogh, K., Key, T., Peters, A., Hampel, R., Concin, H., Nagel, G., Ineichen, A., Schaffner, E., ProbstHensch, N., Künzli, N., Schindler, C., Schikowski, T., Adam, M., Phuleria, H., Vilier, A., Clavel-Chapelon, F., Declercq, C., Grioni, S., Krogh, V., Tsai, M.-Y., Ricceri, F., Sacerdote, C., Galassi, C., Migliore, E., Ranzi, A., Cesaroni, G., Badaloni, C., Forastiere, F., Tamayo, I., Amiano, P., Dorronsoro, M., Katsoulis, M., Trichopoulou, A., Brunekreef, B., and Hoek, G.: Effects of long-term exposure to air pollution on natural-cause mortality: an analysis of 22 European cohorts within the multicentre ESCAPE project, The Lancet, 383, 785-795, doi:10.1016/S01406736(13)62158-3, 2013.

Benkovitz, C. M. and Schwartz, E.: Evaluation of modeled sulfate and $\mathrm{SO}_{2}$ over North America and Europe for four seasonal 
months in 1986-1987, J. Geophys. Res., 102, 25305-25338, 1997.

Brunekreef, B. and Holgate, S. T.: Air pollution and health, The Lancet, 360, 1233-1242, doi:10.1016/S0140-6736(02)11274-8, 2002

Cavanaugh, N. R. and Shen, S. S. P.: The effects of gridding algorithms on the statistical moments and their trends of daily surface air temperature, J. Climate, 28, 9188-9205, doi:10.1175/JCLI-D14-00668.1, 2015.

Chin, M., Ginoux, P., KInne, S., Torres, O., Holben, B. N., Duncan, B. N., Martin, R. V., Logan, J. A., Higurashi, A., and Nakajima, T.: Tropospheric Aerosol Optical Thickness from the GOCART Model and Comparisons with Satellite and Sun Photometer Measurements, J. Atmos. Sci., 59, 461-483, 2002.

Director, H. and Bornn, L.: Connecting point-level and gridded moments in the analysis of climate data, J. Climate, 28, 3496-3510, doi:10.1175/JCLI-D-14-00571.1, 2015.

Dockery, D., Pope, A., Xu, X., Spengler, J., Ware, J., Fay, M., Ferris, B., and Speizer, F.: An association between air pollution and mortality in six U.S. cities, New Engl. J. Med., 329, 1753-1759, 1993.

Ezzati, M., Lopez, A. D., Rodgers, A., Vander Hoorn, S., and Murray, C. J. L.: Selected major risk factors and global and regional burden of disease, The Lancet, 360, 1347-60, doi:10.1016/S0140-6736(02)11403-6, 2002.

Fast, J. D., Gustafson, W. I., Easter, R. C., Zaveri, R. A., Barnard, J. C., Chapman, E. G., Grell, G. A., and Peckham, S. E.: Evolution of ozone, particulates, and aerosol direct radiative forcing in the vicinity of Houston using a fully coupled meteorology-chemistry-aerosol model, J. Geophys. Res., 111, D21305, doi:10.1029/2005JD006721, 2006.

Fuzzi, S., Baltensperger, U., Carslaw, K., Decesari, S., Denier van der Gon, H., Facchini, M. C., Fowler, D., Koren, I., Langford, B., Lohmann, U., Nemitz, E., Pandis, S., Riipinen, I., Rudich, Y., Schaap, M., Slowik, J. G., Spracklen, D. V., Vignati, E., Wild, M., Williams, M., and Gilardoni, S.: Particulate matter, air quality and climate: lessons learned and future needs, Atmos. Chem. Phys., 15, 8217-8299, doi:10.5194/acp-15-8217-2015, 2015.

Goto, D., Dai, T., Satoh, M., Tomita, H., Uchida, J., Misawa, S., Inoue, T., Tsuruta, H., Ueda, K., Ng, C. F. S., Takami, A., Sugimoto, N., Shimizu, A., Ohara, T., and Nakajima, T.: Application of a global nonhydrostatic model with a stretched-grid system to regional aerosol simulations around Japan, Geosci. Model Dev., 8, 235-259, doi:10.5194/gmd-8-235-2015, 2015.

Grell, G. A., Peckham, S. E., Schmitz, R., McKeen, S. A., Frost, G., Skamarock, W. C., and Eder, B.: Fully coupled "online" chemistry within the WRF model, Atmos. Environ., 39, 6957-6975, doi:10.1016/j.atmosenv.2005.04.027, 2005.

Gryspeerdt, E., Stier, P., White, B. A., and Kipling, Z.: Wet scavenging limits the detection of aerosol effects on precipitation, Atmos. Chem. Phys., 15, 7557-7570, doi:10.5194/acp-15-75572015, 2015.

Gustafson, W. I., Qian, Y., and Fast, J. D.: Downscaling aerosols and the impact of neglected subgrid processes on direct aerosol radiative forcing for a representative global climate model grid spacing, J. Geophys. Res.-Atmos., 116, 1-28, doi:10.1029/2010JD015480, 2011.

Hakuba, M. Z., Folini, D., and Wild, M.: Solar absorption over Europe from collocated surface and satellite observations, J. Geophys. Res.-Atmos., 119, 3420-3437, doi:10.1002/2013JD021421, 2014a.

Hakuba, M. Z., Folini, D., Sanchez-lorenzo, A., and Wild, M.: Spatial representativeness of ground-based solar radiation measurements - extension to the full Meteosat disk, J. Geophys. Res.Atmos., 16, 50673, doi:10.1002/jgrd.50673, 2014 b.

Hansen, J., Sato, M., and Ruedy, R.: Radiative forcing and climate response, J. Geophys. Res., 102, 6831-6864, 1997.

Hess, M., Koepke, P., and Schult, I.: Optical Properties of Aerosols and Clouds: The Software Package OPAC, B. Am. Meteorol. Soc., 79, 831-844, doi:10.1175/15200477(1998)079<0831:OPOAAC>2.0.CO;2, 1998.

Huneeus, N., Schulz, M., Balkanski, Y., Griesfeller, J., Prospero, J., Kinne, S., Bauer, S., Boucher, O., Chin, M., Dentener, F., Diehl, T., Easter, R., Fillmore, D., Ghan, S., Ginoux, P., Grini, A., Horowitz, L., Koch, D., Krol, M. C., Landing, W., Liu, X., Mahowald, N., Miller, R., Morcrette, J.-J., Myhre, G., Penner, J., Perlwitz, J., Stier, P., Takemura, T., and Zender, C. S.: Global dust model intercomparison in AeroCom phase I, Atmos. Chem. Phys., 11, 7781-7816, doi:10.5194/acp-11-7781-2011, 2011.

Kinne, S., Schulz, M., Textor, C., Guibert, S., Balkanski, Y., Bauer, S. E., Berntsen, T., Berglen, T. F., Boucher, O., Chin, M., Collins, W., Dentener, F., Diehl, T., Easter, R., Feichter, J., Fillmore, D., Ghan, S., Ginoux, P., Gong, S., Grini, A., Hendricks, J., Herzog, M., Horowitz, L., Isaksen, I., Iversen, T., Kirkevåg, A., Kloster, S., Koch, D., Kristjansson, J. E., Krol, M., Lauer, A., Lamarque, J. F., Lesins, G., Liu, X., Lohmann, U., Montanaro, V., Myhre, G., Penner, J., Pitari, G., Reddy, S., Seland, O., Stier, P., Takemura, T., and Tie, X.: An AeroCom initial assessment - optical properties in aerosol component modules of global models, Atmos. Chem. Phys., 6, 1815-1834, doi:10.5194/acp-6-1815-2006, 2006.

Kipling, Z., Stier, P., Schwarz, J. P., Perring, A. E., Spackman, J. R., Mann, G. W., Johnson, C. E., and Telford, P. J.: Constraints on aerosol processes in climate models from vertically-resolved aircraft observations of black carbon, Atmos. Chem. Phys., 13, 5969-5986, doi:10.5194/acp-13-5969-2013, 2013.

Koch, D., Schulz, M., Kinne, S., McNaughton, C., Spackman, J. R., Balkanski, Y., Bauer, S., Berntsen, T., Bond, T. C., Boucher, O., Chin, M., Clarke, A., De Luca, N., Dentener, F., Diehl, T., Dubovik, O., Easter, R., Fahey, D. W., Feichter, J., Fillmore, D., Freitag, S., Ghan, S., Ginoux, P., Gong, S., Horowitz, L., Iversen, T., Kirkevåg, A., Klimont, Z., Kondo, Y., Krol, M., Liu, X., Miller, R., Montanaro, V., Moteki, N., Myhre, G., Penner, J. E., Perlwitz, J., Pitari, G., Reddy, S., Sahu, L., Sakamoto, H., Schuster, G., Schwarz, J. P., Seland, Ø., Stier, P., Takegawa, N., Takemura, T., Textor, C., van Aardenne, J. A., and Zhao, Y.: Evaluation of black carbon estimations in global aerosol models, Atmos. Chem. Phys., 9, 9001-9026, doi:10.5194/acp-9-9001-2009, 2009.

Koffi, B., Schulz, M., Bréon, F.-M., Griesfeller, J., Winker, D., Balkanski, Y., Bauer, S., Berntsen, T., Chin, M., Collins, W. D., Dentener, F., Diehl, T., Easter, R., Ghan, S., Ginoux, P., Gong, S., Horowitz, L. W., Iversen, T., Kirkevåg, A., Koch, D., Krol, M., Myhre, G., Stier, P., and Takemura, T.: Application of the CALIOP layer product to evaluate the vertical distribution of aerosols estimated by global models: AeroCom phase I results, J. Geophys. Res., 117, D10201, doi:10.1029/2011JD016858, 2012. 
Kovacs, T.: Comparing MODIS and AERONET aerosol optical depth at varying separation distances to assess ground-based validation strategies for spaceborne lidar, J. Geophys. Res., 111, D24203, doi:10.1029/2006JD007349, 2006.

Lequy, É., Conil, S., and Turpault, M.-P.: Impacts of Aeolian dust deposition on European forest sustainability: A review, Forest Ecol. Manage., 267, 240-252, doi:10.1016/j.foreco.2011.12.005, 2012.

Lohmann, U. and Feichter, J.: Impact of sulfate aerosols on albedo and lifetime of clouds : A sensitivity study with the ECHAM4 GCM, J. Geophys. Res., 102, 13685-13700, 1997.

Lohmann, U. and Feichter, J.: Global indirect aerosol effects: a review, Atmos. Chem. Phys., 5, 715-737, doi:10.5194/acp-5-7152005, 2005.

Maher, B., Prospero, J., Mackie, D., Gaiero, D., Hesse, P., and Balkanski, Y.: Global connections between aeolian dust, climate and ocean biogeochemistry at the present day and at the last glacial maximum, Earth-Sci. Rev., 99, 61-97, doi:10.1016/j.earscirev.2009.12.001, 2010.

McTainsh, G. and Strong, C.: The role of aeolian dust in ecosystems, Geomorphology, 89, 39-54, doi:10.1016/j.geomorph.2006.07.028, 2007.

Myhre, G., Samset, B. H., Schulz, M., Balkanski, Y., Bauer, S., Berntsen, T. K., Bian, H., Bellouin, N., Chin, M., Diehl, T., Easter, R. C., Feichter, J., Ghan, S. J., Hauglustaine, D., Iversen, T., Kinne, S., Kirkevåg, A., Lamarque, J.-F., Lin, G., Liu, X., Lund, M. T., Luo, G., Ma, X., van Noije, T., Penner, J. E., Rasch, P. J., Ruiz, A., Seland, Ø., Skeie, R. B., Stier, P., Takemura, T., Tsigaridis, K., Wang, P., Wang, Z., Xu, L., Yu, H., Yu, F., Yoon, J.-H., Zhang, K., Zhang, H., and Zhou, C.: Radiative forcing of the direct aerosol effect from AeroCom Phase II simulations, Atmos. Chem. Phys., 13, 1853-1877, doi:10.5194/acp-13-18532013, 2013.

Pope, V. D. and Stratton, R. A.: The processes governing horizontal resolution sensitivity in a climate model, Clim. Dynam., 19, 211236, doi:10.1007/s00382-001-0222-8, 2002.

Qian, Y., Gustafson Jr., W. I., and Fast, J. D.: An investigation of the sub-grid variability of trace gases and aerosols for global climate modeling, Atmos. Chem. Phys., 10, 6917-6946, doi:10.5194/acp-10-6917-2010, 2010.

Quaas, J., Ming, Y., Menon, S., Takemura, T., Wang, M., Penner, J. E., Gettelman, A., Lohmann, U., Bellouin, N., Boucher, O., Sayer, A. M., Thomas, G. E., McComiskey, A., Feingold, G., Hoose, C., Kristjánsson, J. E., Liu, X., Balkanski, Y., Donner, L. J., Ginoux, P. A., Stier, P., Grandey, B., Feichter, J., Sednev, I., Bauer, S. E., Koch, D., Grainger, R. G., Kirkevåg, A., Iversen, T., Seland, Ø., Easter, R., Ghan, S. J., Rasch, P. J., Morrison, H., Lamarque, J.-F., Iacono, M. J., Kinne, S., and Schulz, M.: Aerosol indirect effects - general circulation model intercomparison and evaluation with satellite data, Atmos. Chem. Phys., 9, 8697-8717, doi:10.5194/acp-9-8697-2009, 2009.

Randles, C. A., Kinne, S., Myhre, G., Schulz, M., Stier, P., Fischer, J., Doppler, L., Highwood, E., Ryder, C., Harris, B., Huttunen, J., Ma, Y., Pinker, R. T., Mayer, B., Neubauer, D., Hitzenberger, R., Oreopoulos, L., Lee, D., Pitari, G., Di Genova, G., Quaas, J., Rose, F. G., Kato, S., Rumbold, S. T., Vardavas, I., Hatzianastassiou, N., Matsoukas, C., Yu, H., Zhang, F., Zhang, H., and $\mathrm{Lu}, \mathrm{P}$.: Intercomparison of shortwave radiative transfer schemes in global aerosol modeling: results from the AeroCom Radia- tive Transfer Experiment, Atmos. Chem. Phys., 13, 2347-2379, doi:10.5194/acp-13-2347-2013, 2013.

Roeckner, E., Brokopf, R., Esch, M., Giorgetta, M., Hagemann, S., Kornblueh, L., Manzini, E., Schlese, U., and Schulzweida, U.: Sensitivity of Simulated Climate to Horizontal and Vertical Resolution in the ECHAM5 Atmosphere Model, J. Climate, 19, 3771-3791, 2006.

Santese, M., De Tomasi, F., and Perrone, M. R.: AERONET versus MODIS aerosol parameters at different spatial resolutions over southeast Italy, J. Geophys. Res., 112, D10214, doi:10.1029/2006JD007742, 2007.

Sayer, A. M., Thomas, G. E., Palmer, P. I., and Grainger, R. G.: Some implications of sampling choices on comparisons between satellite and model aerosol optical depth fields, Atmos. Chem. Phys., 10, 10705-10716, doi:10.5194/acp-10-10705-2010, 2010.

Schell, B., Ackermann, I. J., Hass, H., Binkowski, F. S., and Ebel, A.: Modeling the formation of secondary organic aerosol within a comprehensive air quality model system, J. Geophys. Res.Atmos., 106, 28275-28293, doi:10.1029/2001JD000384, 2001.

Schulz, M., Textor, C., Kinne, S., Balkanski, Y., Bauer, S., Berntsen, T., Berglen, T., Boucher, O., Dentener, F., Guibert, S., Isaksen, I. S. A., Iversen, T., Koch, D., Kirkevåg, A., Liu, X., Montanaro, V., Myhre, G., Penner, J. E., Pitari, G., Reddy, S., Seland, $\varnothing$., Stier, P., and Takemura, T.: Radiative forcing by aerosols as derived from the AeroCom present-day and pre-industrial simulations, Atmos. Chem. Phys., 6, 5225-5246, doi:10.5194/acp-65225-2006, 2006.

Schutgens, N. A. J., Nakata, M., and Nakajima, T.: Validation and empirical correction of MODIS AOT and AE over ocean, Atmos. Meas. Tech., 6, 2455-2475, doi:10.5194/amt-6-2455-2013, 2013.

Schutgens, N. A. J., Partridge, D. G., and Stier, P.: The importance of temporal collocation for the evaluation of aerosol models with observations, Atmos. Chem. Phys., 16, 1065-1079, doi:10.5194/acp-16-1065-2016, 2016.

Seinfeld, J. H. and Pandis, S. N.: Atmospheric chemistry and physics: from air pollution to climate change, John Wiley \& Sons, Hoboken, New Jersey, 2nd Edn., 2006.

Shinozuka, Y. and Redemann, J.: Horizontal variability of aerosol optical depth observed during the ARCTAS airborne experiment, Atmos. Chem. Phys., 11, 8489-8495, doi:10.5194/acp-11-84892011, 2011.

Simpson, D., Benedictow, A., Berge, H., Bergström, R., Emberson, L. D., Fagerli, H., Flechard, C. R., Hayman, G. D., Gauss, M., Jonson, J. E., Jenkin, M. E., Nyíri, A., Richter, C., Semeena, V. S., Tsyro, S., Tuovinen, J.-P., Valdebenito, Á., and Wind, P.: The EMEP MSC-W chemical transport model - technical description, Atmos. Chem. Phys., 12, 7825-7865, doi:10.5194/acp-127825-2012, 2012.

Smith, K. R., Jerrett, M., Anderson, H. R., Burnett, R. T., Stone, V., Derwent, R., Atkinson, R. W., Cohen, A., Shonkoff, S. B., Krewski, D., Pope, C. A., Thun, M. J., and Thurston, G.: Public health benefits of strategies to reduce greenhouse-gas emissions: health implications of short-lived greenhouse pollutants, The Lancet, 374, 2091-103, doi:10.1016/S0140-6736(09)617165, 2009.

Stier, P., Schutgens, N. A. J., Bellouin, N., Bian, H., Boucher, O., Chin, M., Ghan, S., Huneeus, N., Kinne, S., Lin, G., Ma, X., Myhre, G., Penner, J. E., Randles, C. A., Samset, B., Schulz, M., 
Takemura, T., Yu, F., Yu, H., and Zhou, C.: Host model uncertainties in aerosol radiative forcing estimates: results from the AeroCom Prescribed intercomparison study, Atmos. Chem. Phys., 13, 3245-3270, doi:10.5194/acp-13-3245-2013, 2013.

Stroud, C. A., Makar, P. A., Moran, M. D., Gong, W., Gong, S., Zhang, J., Hayden, K., Mihele, C., Brook, J. R., Abbatt, J. P. D., and Slowik, J. G.: Impact of model grid spacing on regionaland urban- scale air quality predictions of organic aerosol, Atmos. Chem. Phys., 11, 3107-3118, doi:10.5194/acp-11-31072011, 2011.

Swap, R., Garstang, M., Greco, S., Talbot, R., and Kallberg, P.: Saharan dust in the Amazon Basin, Tellus B, 44, 133-149, doi:10.1034/j.1600-0889.1992.t01-1-00005.x, 1992.

Textor, C., Schulz, M., Guibert, S., Kinne, S., Balkanski, Y., Bauer, S., Berntsen, T., Berglen, T., Boucher, O., Chin, M., Dentener, F., Diehl, T., Easter, R., Feichter, H., Fillmore, D., Ghan, S., Ginoux, P., Gong, S., Grini, A., Hendricks, J., Horowitz, L., Huang, P., Isaksen, I., Iversen, I., Kloster, S., Koch, D., Kirkevåg, A., Kristjansson, J. E., Krol, M., Lauer, A., Lamarque, J. F., Liu, X., Montanaro, V., Myhre, G., Penner, J., Pitari, G., Reddy, S., Seland, $\varnothing .$, Stier, P., Takemura, T., and Tie, X.: Analysis and quantification of the diversities of aerosol life cycles within AeroCom, Atmos. Chem. Phys., 6, 1777-1813, doi:10.5194/acp-6-1777-2006, 2006.

Textor, C., Schulz, M., Guibert, S., Kinne, S., Balkanski, Y., Bauer, S., Berntsen, T., Berglen, T., Boucher, O., Chin, M., Dentener, F., Diehl, T., Feichter, J., Fillmore, D., Ginoux, P., Gong, S., Grini, A., Hendricks, J., Horowitz, L., Huang, P., Isaksen, I. S. A., Iversen, T., Kloster, S., Koch, D., Kirkevåg, A., Kristjansson, J. E., Krol, M., Lauer, A., Lamarque, J. F., Liu, X., Montanaro, V., Myhre, G., Penner, J. E., Pitari, G., Reddy, M. S., Seland, Ø., Stier, P., Takemura, T., and Tie, X.: The effect of harmonized emissions on aerosol properties in global models an AeroCom experiment, Atmos. Chem. Phys., 7, 4489-4501, doi:10.5194/acp-7-4489-2007, 2007.
Twomey, S.: Pollution and the planetary albedo, Atmos. Environ., 8, 1251-1256, 1974.

Vink, S. and Measures, C.: The role of dust deposition in determining surface water distributions of $\mathrm{Al}$ and $\mathrm{Fe}$ in the South West Atlantic, Deep-Sea Res. Pt. II, 48, 2787-2809, doi:10.1016/S09670645(01)00018-2, 2001.

Weigum, N., Schutgens, N. A. J., and Stier, P.: Effect of aerosol subgrid variability on aerosol optical depth and cloud condensation nuclei: Implications for global aerosol modelling, Atmos. Chem. Phys. Discuss., submitted, 2016.

Weigum, N. M., Stier, P., Schwarz, J. P., Fahey, D. W., and Spackman, J. R.: Scales of variability of black carbon plumes over the Pacific Ocean, Geophys. Res. Lett., 39, L15804, doi:10.1029/2012GL052127, 2012.

Williamson, D. L.: Convergence of aqua-planet simulations with increasing resolution in the Community Atmospheric Model, Version 3, Tellus A, 60, 848-862, doi:10.1111/j.16000870.2008.00339.x, 2008. 